\title{
Organic Creativity and the Physics Within
}

Mea M. M. Lowcre

John Benjamins Publishing Company 


\section{Lorentz center}

NIAS

Scientific I Johan Hoorn, NIAS \& VU Amsterdam

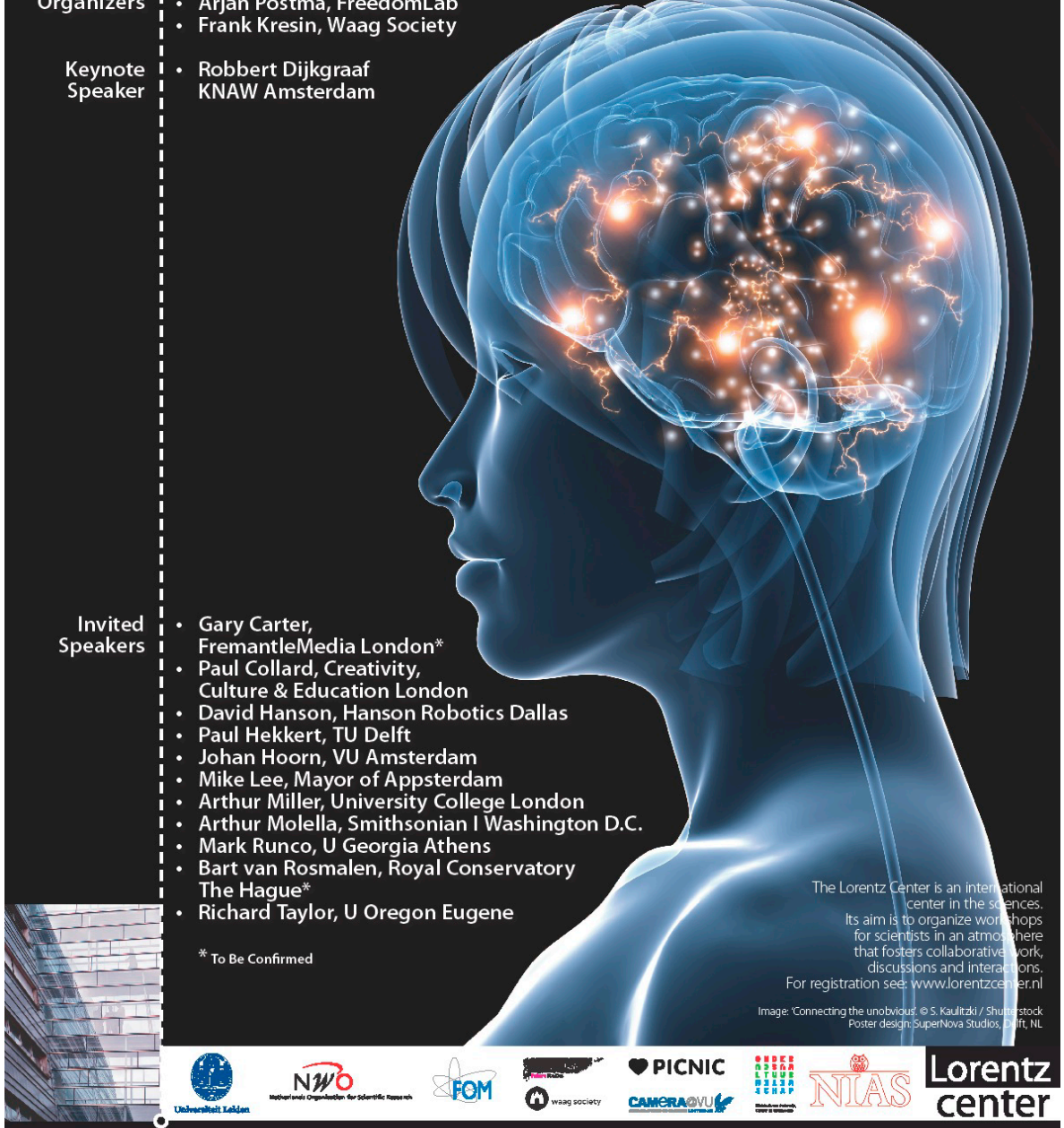

$w$ w $w$. I o r e $n t z c$ e $n t e r . n$ I




\section{Organic Creativity and the Physics Within}

Edited by

Johan F. Hoorn

Vrije Universiteit Amsterdam

With contributions by Mea M.M. Lowcre:

$\begin{array}{ll}\text { Martijn Arts } & \text { Henriette Jensenius } \\ \text { Michel Avital } & \text { Diana Krabbendam } \\ \text { Karim Bennamar } & \text { Frank Kresin } \\ \text { Thieu Besselink } & \text { Annewies Kuipers } \\ \text { Wouter Boog } & \text { Theo Kuipers } \\ \text { Paul Collard } & \text { Mike Lee } \\ \text { Simon Colton } & \text { Valesca Lindenberg } \\ \text { Cecile Corneille } & \text { Jessica Lowe } \\ \text { Desmond Germans } & \text { Larissa Mendoza Straffon } \\ \text { Sylvia Gielink } & \text { Arthur I. Miller } \\ \text { Amanda Hanson } & \text { Arthur Molella } \\ \text { David Hanson } & \text { Timen Olthof } \\ \text { Paul Hekkert } & \text { Chris Ott } \\ \text { Carla Hoekendijk } & \text { Marco Otte } \\ \text { Johan F. Hoorn } & \text { Wim Poelman } \\ \text { Syed Waqar Jaffry } & \text { Matthijs Pontier }\end{array}$

Arjan Postma Loren Roosendaal Vincent Rump Mark Runco Arnold Smeulders Richard Taylor Jaap van den Herik Katinka van der Kooij Jörgen van der Sloot Onno van der Veen Geke van Dijk Peter van Gorsel Bart van Rosmalen Jacco van Uden Jeroen Werner

John Benjamins Publishing Company Amsterdam/ Philadelphia 
ISBN 978902721203 O (E-BOOK)

(C) 2013 - John Benjamins B.V.

This book is made available under a CC BY-NC-ND 3.0 license.

http://creativecommons.org/licenses/by-nc-nd/3.0

John Benjamins Publishing Co. · P.O. Box 36224 · 1020 ME Amsterdam · The Netherlands John Benjamins North America · P.O. Box 27519 · Philadelphia PA 19118-0519 • USA 


\section{Table of contents}

$\begin{array}{lr}\text { Acknowledgments } & 6\end{array}$

$\begin{array}{ll}\text { Preface } & 7\end{array}$

1. Introduction 9

2. History 11

3. Physical creativity $\quad 14$

3.1 Making novel combinations is the universal mechanism $\quad 15$

3.2 Creativity at different scales 16

3.3 Psychological creativity 18

3.4 Boundaries of creativity: From entropy to near-stability and back 21

3.5 The number of combinatory possibilities exceeds the observable universe $\mathbf{2 3}$

3.6 Within the sinusoid boundaries: Fractal emergence 25

4. Perception as a limiter, perception as a fuser

4.1 Perceptual error: Making room for creativity $\mathbf{2 8}$

4.2 Epistemic considerations 30

4.3 Language and signs 34

5. Human creativity

\subsection{Playfulness 40}

6. Implications

6.1 Holistic model 42

6.2 Creativity in all, creativity for all 43

6.3 Implications for human cognition 46

6.4 A double consciousness: Implications for the concept of self 47

6.5 Autonomous creativity and ethical restrictions $\quad 41$

6.5.1 The dogma of novelty 48

6.5.2 Creativity of the crowds 50

6.6 New ways of working 51

7. Conclusions

8. Coda: Futurist perspectives $\quad 56$

$\begin{array}{ll}\text { References } & 57\end{array}$

$\begin{array}{ll}\text { Appendix } 1 & 61\end{array}$ 


\section{Acknowledgments}

We are grateful to the Lorentz Center and the scientific committee for providing us with the opportunity to organize an international workshop and to write this publication. The Netherlands Institute for Advanced Study (NIAS) and the Rector are kindly acknowledged for their support during the application process. We thank Max Louwerse and Sonia Zyngier for being critical as well as open-minded to our conceptualizations. The open-access publication was made possible by the Creative Industries Scientific Program (CRISP) supported by the Ministry of Education, Culture and Science. 


\section{Preface}

In September 2011, an awesome group of people gathered for five days at the Lorentz Center in Leiden to break new ground in the theory of creativity. They were scientists, artists, entrepreneurs, engineers, students, laymen, and professionals from diverse backgrounds. We welcomed Robbert Dijkgraaf, mathematical physicist and string theorist, director of the Princeton Institute for Advanced Study. Psychologist Mark Runco of the Torrance Creativity Center also attended as well as historian Art Molella of the Smithsonian's Lemelson Center for the Study of Invention and Innovation. David Hanson, top-tier technician in robotics and Mike Lee, the world's toughest programmer and self-acclaimed "Mayor of Appsterdam" contributed to our cause as did physicist Richard Taylor, the man who discovered fractal patterning in Jackson Pollock's abstract paintings. Insights of genius were shared with us by science philosopher Arthur Miller and Paul Collard showed us how to invigorate educational curricula through creativity.

These people had but one mission (cf. Ambrose, 1996): To come as closely as possible to the lay-out of a unified account of creativity, across disciplines, across schools, and across methodological differences. This in itself was a worthy cause from a viewpoint of deep science but with practical merit as well. Gradually, societies and economies transition from industrial production to conceptual innovation but creativity as a notion is ill-defined, the process but partially understood, and the conditions under which it flourishes well-known but hardly implemented. Such a situation does not spur the uptake of post-industrial global collaborations. Creativity is shattered over occupational areas, with its own jargon and concerns, whereas it unites all living creatures and nature in itself as we will argue.

The digestion of the lectures, deliberations, and design sessions can be found in this here book. It is not a conference proceedings, not an edited volume, not a text book, and it is not an anthology. It is a multi-authored essay, close to a monograph, featuring original theory in which all contributions are regarded equal whether delivered visually, aurally, or in writing. This in itself makes this piece of work unique and an act of egalitarian co-creation. In this sense, the book is unrivaled but some of its closest predecessors could be Schrödinger (1944/2010) on the physical aspects of life formation, Kelly (2010) on the exponential accumulation of technology, or as a journal paper: Goswami (1996) on the quantum of creativity. 
Organic Creativity and the Physics Within is not a collection of single contributions but a full integration or better co-creation of knowledge and ideas put forth by a most diverse and top quality group of people. This effort was not "academics only." Science profited largely from the experience of practitioners such as designers, artists, and entrepreneurs. It was not "professors only." Fresh ideas came from students and novices alike. Due to the multitude of disciplines - from mathematical physics to arts, history, and philosophy - there were ample opportunities for creativity to transpire and so it did.

The contribution is unique in that it explicitly connects the creativity found in physical nature to the creativity found in organisms, in particular, humans. The tenets of the theory are three-fold: Creativity is combinatory, focused on the complementary of features, and susceptible to fractal emergence. The beauty of this approach is that it leaves room for playfulness and intuition but that the account is mathematical, including combinatorics, fuzzy logics, and fractal algorithms. The main difference between creativity in the physical world and human creativity is that the first is largely based on coincidence ('serendipity') and that humans can harness and accelerate that serendipity more efficiently through a deliberate and more systematic search of the solution space.

The book is for scholarly and practical use. It is a brief introduction and first push into a transdisciplinary view on creativity. Because it was written by academics, artists, students, and practitioners, it is fit for academics, artists, students, and practitioners. The style is accessible but the contents are bewildering.

The authors joined their names in a pseudonym: Mea M. M. Lowcre. This stands for Lorentz Workshop on Creativity: Meaning, Mechanisms, Models, the heading under which we gathered at Leiden University. ${ }^{1}$ 


\section{Introduction}

Through the ages, philosophers, scientists, dreamers, and children alike, have pondered the mystery of origins. Where do we come from? What are the origins of existence, our world, life, people, mind, and ideas themselves? We also wonder: Just what is the origin of origins? How do new things come into existence at all? Are humans the center of all creativity - the sole purveyors of creativity in the universe? Or are we merely a special case of the creativity that is at play throughout the cosmos? Beyond mere philosophy, understanding of creativity may have practical implications. If we can understand creativity, we may boost human ingenuity. We could teach great creativity in our schools, and foster improved cultures of creativity in science, business, politics, and so on. We could apply civilization's enhanced creativity to the wicked problems that afflict us problems which require those extraordinary breakthroughs that only extraordinary creativity may provide.

To wrestle with these questions in a new, creative way, the Lorentz Workshop on Creativity (Lowcre) of 2011 brought together thought leaders as well as students to form an interdisciplinary team of physicists, psychologists, artists, historians, industrial designers, computer scientists, and others in a week of lectures and exercises intended to generate creative breakthroughs on the questions of creativity. The participants found themselves by turns illuminated by scintillating perspectives, and frustrated by differences in belief; warmed by shared purpose, but disoriented by widely differing jargon about creativity. However, through the week's immersive experiences which engendered trust and collaboration, the differing languages were translated, disparate perspectives were brought into closer alignment, and a holistic perspective on creativity began to emerge.

The Lowcre team considered a widely diverse set of perspectives on creativity, and a virtual menagerie of different examples of creativity, from that of the artist, to scientists like Einstein and Feynman, corporate teams of designers, to such creative natural processes as star formation and the birth of all structure in the universe. Considered also were questions of biological emergence and evolution, complexity physics as well as fractal phenomena. From the human perspective, we discussed the wonders of creativity, the psychology and the fostering of the conditions of creative thinking. We considered the physics of creativity, life and mind. We discussed the wonder that, contrary to information 
physics, new patterns of matter and energy (including those patterns we call life and mind) pop into existence at all. We mused about mechanisms of creativity how diverse forms of creativity may function, and more: Whether some unifying mechanisms may interconnect these forms, which, if formulated as principles may provide a foundation of a new science of creativity - a "unified theory of creativity," if you will.

By the end of our deliberations, we believe we identified some regularity that may underlie creativity at many different levels, from pattern emergence in fundamental physics, to the emergence of life, to the creativity of the individual and society. These results are preliminary, no more than a sketch, and require additional research. But the implications of an interdisciplinary science of creativity are potentially quite profound. The wider perspectives of an integrative approach may provide discoveries that no separate narrow discipline could. Each of the numerous sub-disciplines may be invigorated by fresh ideas, perturbing dogma and "well-worn ruts" that famously impede progress in established communities.

Yet, there were inevitably many issues raised that remained unanswered. For instance, if all the creative processes are indeed one, then would such a unitary principle describe the origin of life, reality, human consciousness, and human ideation? Maybe we are hard-wired to wonder where stuff comes from. Perhaps our probing minds naturally hunger to know all the secret mechanisms of our existence. Certainly creativity happens. Every single thing is new at some point in history. But where does creativity come from? Information theory says that information can be neither created nor destroyed. But patterns, irreducible and new, do emerge. Would the answer lie in complexity physics, combined with human neurobiology, evolutionary psychology, and cognitive psychology in general, guided by intuitive hypotheses about creativity? If we can unlock the principles, can we harness creativity more effectively? Can we better foster human genius? Can we apply these principles more generally and abstractly to achieve self-assembling molecular machines, or to realize machines "who" think as creatively as people do, or even more so? What about the ethics of creativity? We value creativity, and we sometimes fear it as well. Wonders happen when genius-level creativity serves humanity, but horrors result when such genius serves the psychotic dictator. What Pandora's Box may unbridled creativity open?

In the next sections we explore a combinatory account of creativity that starts from physics and ends with playfulness. In addition, implications of our framework are contemplated for new ways of working, the concept of self, and ethics. But first we realize that we are part of a long history of humankind attempting to revitalize or even overthrow tradition through the unleashing of human creativity. 


\section{CHAPTER 2}

\section{History}

All the buzz today around the terms creativity, novelty, and inventiveness would make you think we are onto something utterly new. In fact, history reveals many prior calls for a richer, more creative educational and cultural environment. The cyclical rise of romantic movements since the beginnings of Western civilization is prime evidence of a perceived recurrent need for creative interventions, albeit in other guises. Just think of J. J. Rousseau's plea for emotional sensibility and intuition, based on a romantic concept of genius in the pursuit of truth, in an Age of Reason (Hahn, 1971). Substitute "creativity" for "genius" or "sensibilité," while ratcheting down his rhetoric a notch, and he sounds remarkably contemporary. To generalize a bit, romantic, emotional, organic eras seem to alternate with rational, analytical, mechanistic eras like, well... clockwork (a type of action and reaction). And, just as the Jacobins invoked the name of Rousseau in the French Revolution, the switch between one worldview to the other often seems triggered by some sort of social-cultural crisis (Hahn, 1971).

A prime historical example of this phenomenon occurred amidst the Second Industrial Revolution, particularly after the World War I, when a vociferous group of cultural critics blamed the War on a materialist, technology-obsessed society, and on specialized, overly rational, unimaginative ways of thinking. They represented one side of the famous "Machine Debates" about the social-cultural impacts of automation and mass production. Greatly over-simplified, their argument linked an over-emphasis on specialized, rational knowledge with the fragmentation of the human personality, and the consequent fraying of the social fabric. Ergo, World War I. Their calls for reform invoked holism, emotional balance, and an organic, non-mechanistic view of science, nature, man, and of technology itself. One can read "creativity" and "inventiveness" into this call to action without distorting their views.

Among the most visible leaders of the battle were two like-minded thinkers, the American social critic and technology historian Lewis Mumford and the Swiss art historian Sigfried Giedion, tireless promoter of the Bauhaus movement. In Technics and Civilization, Mumford (1934) advocated a concept of "organic mechanism," a (re) vitalized vision of technology and the natural world based on the writings of his mentor, the eccentric Scots urban theorist Patrick Geddes, 
one of the planners of New Delhi, advocate of holism, and, by any measure, an outrageously creative thinker. Mumford hoped thereby to reintegrate man into nature and the cosmos. Holistic ideas of man and nature were in the air. Thus, the American philosopher, psychologist, and educational reformer John Dewey (1916) argued for hands-on, inquiry-driven childhood learning based on direct experience of the natural and material worlds.

Even more explicit along these lines was Sigfried Giedion, Mumford's kindred spirit, author of the modern architect's Bible, Space, Time and Architecture (1941), and of Mechanization Takes Command (1948), a book still prized today by museum curators around the world. In treatises that book-ended World War II, he warned in apocalyptic terms of the imminent demise of civilization, unless man renounced mechanistic technologies of human destruction, either in war zones or the work place (Molella, 2002). Again, the fault lay in man's splintered thinking, born of narrow specialization and over-reliance on reason at the expense of emotion. Man's personality is out of balance, asserted Giedion, and the only way to restore "equipoise" in both humans and the world was to adopt a more holistic, emotion-rich, aesthetic view of the cosmos. As the title to his masterwork Space, Time and Architecture suggests, Einsteinian Relativity provided the appropriate framework for his model cosmos - chiefly because Giedion believed it uniquely combined artistic and scientific understanding within a human-centered, nonmechanistic frame. Picasso's Cubism and Relativity, he argued, were cut from the same cloth. He also espoused a novel way of perceiving the Whole through the newly fashionable principles of Gestalt psychology. Notice how, in Giedion's thinking, revolutionary and creative ways of thinking about nature, including about the origins of the cosmos, seamlessly connect to creativity in all other human domains, artistic and humanistic.

Both Mumford and Giedion captured the spirit of their time and attracted a loyal following, but, in the end, unfortunately, their views gained little traction in post-War Europe and America, where technology and materialism continued to surge blindly ahead. With the electronics and computer revolutions, the moon landing, genetic engineering, and similar ground-breaking developments, technology seemed to jump from one triumph to the next. Never mind the environmental dissenters or the ban-the-bomb "crazies." Specialization and rationality reigned.

What has precipitated the most recent challenge to that status quo are the diminishing economic returns from science-and-technology-as-usual, the abysmal state of education in Western countries, Post-Industrialism, and environmental problems that can no longer be ignored (e.g., Newsweek (July 10, 2010), 
The Creativity Crisis; ${ }^{2}$ The Atlantic (March 25, 2011), The Creativity Crisis: Why American Schools Need Design). 3 The usual ways in education, production, and policy just do not seem to cut it anymore, nor does just muddling through. In short, we are once again in crisis. Only true leaps of mind will do, and a renewed commitment to creative understanding and habits seems like the best and only remedy. We are now, in fact, on the cusp of a revived creative agenda. If, as we have seen, that agenda is not entirely new, it involves creativity with a new sophistication and in a new key. ${ }^{4}$ At least that is our hope. Wiser in our ways, perhaps, both with an eye to the past and a more profound understanding of the creative process in nature and within ourselves, we are poised to strike out more confidently on a new, more innovative path. With Pope (2005), we wonder if a single shared understanding of creativity is possible not only within the humanities but also within the physical sciences, comparing creativity in nature with its materialization in the arts, literature, and social sciences.

2. http://www.thedailybeast.com/newsweek/2010/07/10/the-creativity-crisis.html

3. http://www.theatlantic.com/national/archive/2011/03/the-creativity-crisis-why-americanschools-need-design/73038/

4. See, for instance, http://www.youtube.com/watch?v=zDZFcDGpL4U 


\section{Physical creativity}

We believe that creativity is the production or emergence of novel combinations out of existing components and that it occurs at all levels of organization of the physical and psychological world. It ranges from sub-atomic particles to the subconscious and conscious thoughts of organisms. In putting existing entities together to create entities that never existed before, nature, at its basic level, is in some sense "creative." This also means that new synthetic combinations generated by machines can be regarded as creative in a physical sense.

With this position - creative novelty taking place independent of human agency - we got ourselves deeply into trouble. One could righteously counter that "if a tree falls in a forest and no one is around to hear it, does it make a sound?" At least from a psychological perspective, moving molecules themselves do not constitute sound. Only when those molecules touch hair cells in the (functioning) cochlea, we can speak of sound. Something similar may be said for creativity. The coincidental grouping of items would not constitute creativity, only the novel combination of entities would. For something to be novel more is needed than its presence (i.e. more is needed than moving molecules). If creativity is not related to a conscious mind, it seems as if consciousness or even intention in the 'sender' (creator) and/or 'receiver' (interpreter) are inessential to speak of creativity.

Creativity happens - but indeed a human observer is needed to recognize it and qualify its outcomes as 'new.' An ear is needed to hear the sound of the falling tree but that does not mean that the air molecules do not move around and exert their influence, making other objects tremble than cochlear hair cells alone. Inorganic nature shows plenty of examples of combination making, some of which humans experience as novel. Through investigation of, for instance, speciation and cross-breeding or reasoning back through cosmological time, one can infer that non-human nature evolves from older forms to forms unprecedented in history - novel forms, a human would say. Therefore, the claim can be made that nature is creative without humans noticing although a human consciousness is required to acknowledge the fact that creation occurred at all. Things may happen unseen. One could even argue that through the development of human consciousness, nature recognizes that sometimes (coincidental) combination making leads to something entirely new. 


\subsection{Making novel combinations is the universal mechanism}

There are plenty of frameworks and models that address (parts of, at least) the issues and factors that pertain to creativity (e.g., Greene, 2001; 2004). ${ }^{5}$ Greene provides a summary in which he juxtaposes virtually all the core theories and concepts that are around, comparing and contrasting them vis-a-vis some common benchmarking criteria. It may well be that many of these theories make sense in themselves but the sheer number of them also makes one wonder whether there is something more fundamental that may underlie them all. Based on Greene (2004), we played with a host of creativity models listed in Appendix 1. They range from accounts of "courage" to "fine tuning;" they may be Darwinian or advocate a "social marketing" strategy or they focus on insight, performance, or start from combinatory theories. We decided on the latter approach as our vantage point because the simplicity of combination theory can deal with emergent aspects of creativity that occur in the natural world as well as in human creativity. A matter of parsimony.

One common approach to creativity is the juxtaposition of disparate ideas in order to make something new and useful or appropriate (e.g., Csíkszentmihályi, 1996:9; Albert \& Runco, 1999:25; Miller, 2000:324; Moran, 2010: 78-79). While adopting that assumption in general in Lowcre, we scrutinized the physics of creation as related to the psychology of creativity. We argue that making novel combinations in nature can take place without involving any human agency. In other words, combinations can be new as a function of accidental collisions or contingencies of different types of matter without requiring anyone to observe that emergence of new combinations and judge it as 'novel,' 'useful,' 'appropriate,' and make selections.

There is also psychological creativity as a willful act of an organism (e.g., Barron, 1988) - and sometimes as serendipitous coincidence (e.g., JohnsonLaird, 1988) - that combines two entities and merges them into one new concept or object. ${ }^{6}$ It follows then that there may be a physical novelty not recognized by a human mind, physical novelty that is psychologically acknowledged, psychologically perceived novelty that can be considered a first time ever combination of ideas or objects, and psychologically perceived novelty that has been around physically for thousands of years and merely is a first time discovery by the observer.

5. Also check out http://xhyragraf.com/2007/01/18/model1/ and beyond.

6. Also see http://www.youtube.com/watch?v=NugRZGDbPFU 


\subsection{Creativity at different scales}

The earliest stages of the universe displayed almost no patterns of organization. Following that inchoate stage, particles, atoms, galaxies and stars began to evolve, eventually producing the heavy elements. From a primordial soup full of hydrocarbons, with water as the universal solvent, amino acids produced life, eventually leading to entities with nervous systems, some becoming primates and, ultimately human beings, only minutely different from chimps genetically, nevertheless differing profoundly from their nearest primate relative. And with the rise of Homo sapiens, culture, technology, and augmented intelligence came into being.

If physical combination and psychological combination are happening simultaneously, then creativity takes place at many different scales of data aggregation. If we approach all matter and ideas as data points in a universe of information, then creativity happens at sub-atomic levels (cf. quantum uncertainty), at the molecular level (e.g., the first time that $2 \mathrm{H}+\mathrm{O} \rightarrow \mathrm{H}_{2} \mathrm{O}$ ), at the level of objects and matter (e.g., two stars colliding), at the level of organisms (e.g., algae and fungus become lichen), the level of ideas (e.g., metaphysics plus quantum physics become quantum metaphysics), and so forth. Therefore, we believe that creativity takes place in a scale-independent way.

At the sub-atomic level, quantum uncertainty governs the interaction between real and virtual particles. Out of these interactions, ruled by physical laws, elementary particles arise. Collisions between constituent particles create new particles, both long and short-lived, that form more combinations, more informational units, to fuel the ongoing creation of particles and matter. As the universe continuously cools down and the basic sub-atomic particles form, the process persists at the larger scale of molecules. Molecular hydrogen, helium, and other light elements emerge continuously.

Each of these steps sometimes creates not only something new, but also something that enables the creation of still new entities. In this way we can regard the formation of stars and planets as the result of a physical process of combining separate and distinct entities into new ones. The first star and the first planet were at the moment of their genesis truly a novel and emergent property of the atomic and molecular soup of the universe. The continuous iteration of this process results in micro entities that combine into macro entities of ever increasing complexity.

Eventually, this physical creativity proves capable of crafting living organisms notably humans, who apply particular principles to judge the creative outcomes not only on the basis of physical law, but also in terms of continued existence (e.g., selection, adaptation). Although this may not be a conscious process, it immensely increases the space for being creative, as it allows for building new solutions 
upon previous successes, thus reducing (but not excluding) the role of chance (cf. serendipity). DNA is nature's glory because it is one of the few molecules known so far that can store information about itself and duplicate itself with only the tiniest inconsistencies. These 'errors' are actually not errors because through random mutations, the reproductive systems of organisms are able - on the grandest scale - to rapidly increase the rate of generating new creatures (e.g., cynodont, archaeopteryx, platypus, lichen). Organic creativity speeds up the combinatory process in comparison to the slow astronomical timescale of creation in the physical universe. DNA holds on to previous information through storage in the genes. This way, during the combination of two genomes, it increases the number of information units that can be accessed with minor effort for combinatory purposes. The reproductive side is the continuity aspect of this creative process, whereas disruption follows from the random mutations that may sometimes occur.

Yet, at the level of organisms and particularly humans, the universe, it may be said as a kind of anthropomorphism, consciously reflects upon itself and on what it has created. If we regard ourselves as a living part of the universe, through us, the universe found a way to optimize or willfully change a new combination into something else or use it in yet another combination, accumulating a pile of new combinations out of the old ones. In other words, DNA mutation may be nature's way to accelerate the combinatory process through organisms; human organisms speed up that acceleration by exploring the potential of creating all possible combinations mentally. This may lead to combinatory explosion (see next) but is limited by the number of information units available to the human creator. The number of novel combinations that are possible decreases as more combinations are made.

Thus, when creativity is physical, it is based on coincidence or 'chaos;' when psychological, it is based on coincidence in accord with a willful search for connections between (psychologically) remote domains. After that, all kinds of selection criteria, evaluations, and judgments may help the (human) creator to fine-tune the novel combination to specific needs, aesthetics, appropriateness to a cultural context, etc. Creativity is search followed by alteration, modifying that search (Schank, 1988:221). In doing so, the information space to come up with alternative solutions closes in, becoming ever narrower. The evolution of an innovation line will be disrupted only by chance or because the environment changes such that the evolutionary line falls into crisis and, in order to survive, changes itself by making a disruptive jump to another domain.

The step-wise "stages" or scales at which creativity occurs should not be perceived as sharp boundaries between less and more creativity. The boundaries between inanimate objects and life, between species (e.g., are fungi animals or plants?), and between psychological and physical creativity are to be treated as 
fuzzy. The "evolution" of the creative process is continuous with certain occasional disruptions, which may be purposeful or coincidental (cf. Perkins, 1988; Simonton, 1988), but which cannot be quantified in a number of discrete steps.

\subsection{Psychological creativity}

At all scales, the mechanism of creativity probably is of a combinatory nature, a self-propelled emergence of interactions that never occurred before between entities (or that are perceived as such). Yet, in the absence of a conscious mind, how can it be that creativity is self-propelled? Should not there be human agency involved that wants to create? No. In physical and biological nature, one novel combination leads to generations of updates and upgrades. Sometimes, completely new crossovers happen, building on top of one another. This process happened way before humans entered the stage and continues long after humans will exit. Therefore, there must be a self-propulsion in creativity that goes beyond human agency and the willful act to create (which is undeniably present as well). Thus, natural or better physical creativity happens in all of us and human creativity brings something extra, which has to do with quickly optimizing the apparent similarity between domains.

In physical nature, distinctive but complementary features attract; psychologically, complementary and similar features attract. The only features that resist combination are those distinctive features that do not establish some local equilibrium, in energy efficiency (physics) or conceptual fit (psychology). When two sodium atoms reacted for the first time with chlorine, they formed two molecules of sodium chloride (or table salt). This did not happen because the components were identical $\left(2 \mathrm{Na} \neq \mathrm{Cl}_{2}\right)$ but because they were complementary, locally establishing more energy efficiency together than each on their own. The result was a decrease in dissimilarity. The combination of $2 \mathrm{NaCl}$ (sodium chloride) is more similar to $2 \mathrm{Na}$ (sodium) and to $\mathrm{Cl}_{2}$ (chlorine) than sodium and chlorine are to each other. To establish a reaction it is critical that components are distinctive and that the combination leads to a reduction of dissimilarity (or an increase in similarity) compared to the earlier situation. As table salt, sodium and chlorine share a set of electrons - chemical bonds have a percentage of covalency. By contrast, two identical molecules will not result into something new. One water molecule plus another water molecule makes two water molecules.

In psychology, it works the same way. One spoon next to another identical spoon results into two identical spoons. The spoon becomes novel once it is combined with an entity of an entirely different class, for example, a snake. Snake has distinctive features such as head and tail that are complementary to a spoon. You 
can put the head on top of the scoop and put the handle on top of the tail to create a spoon that looks like a cobra (Figure 1). Of course, human creativity is not merely a matter of combination because all kinds of optimizations and adaptations take place (see Hoorn, 2002) to make the cocktail spoon look like a cobra. But the combinatory core of creativity can be simulated by a computer relatively simple.

Actually, we made a software system based on Hoorn (2002) that can make combinations between associatively remote entities. At the Lorentz Workshop, the conceptual similarity between snake and spoon (long, lean, and curved) was suggested by that same software during a demonstration. The elaboration such as the choice for the type of spoon and making the snake of metal wire, obviously, was human.

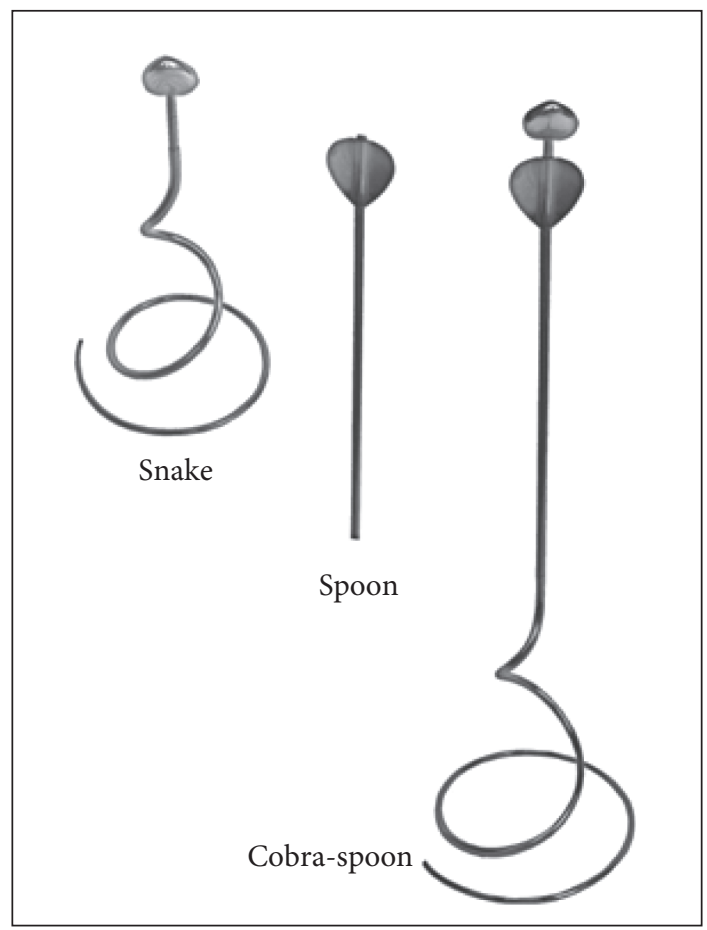

Figure 1. Snake plus cocktail spoon combine into cobra-spoon.

Different probably from combination making in nature, however, is that human creativity indeed uses distinctive complementary features but does this at the foresight of increasing the similarity between entities; something physical nature probably does not foresee. Humans can make a conceptual merger in their heads before actually trying things out (cf. Arnheim, 1954; McKim, 1972; Wenger \& 
Poe, 1996). The difference with animals is that humans can associate and "simulate" through causal models a new reality to a far larger extent (cf. Sci-Fi) than animals. Animals probably do not associate conceptual knowledge or apply causality other than related to their physical environment in the here and now. A beaver builds a dam by comparing its 'knowledge' about building dams with the available materials and the local circumstances.

For creativity to occur, then, features should be distinctive and they combine on the basis of complementarity. As an extra of human creativity, features can also combine when they are similar but belong to disparate entities that do not have to be physically present. In all cases, the result is a reduction of dissimilarity. Physical creativity may happen without any intelligence being involved, also in humans (cf. serendipity). A machine can simulate it (Figure 1) and psychological studies repeatedly found that intelligence is hardly correlated with being creative (e.g., Sternberg \& O’Hara, 1999: 262; Nickerson, 1999:396; Heilman, Nadeau, \& Beversdorf, 2003; Park, Lubinski, \& Benbow, 2007).

Broadly speaking, the mind classifies the data it observes in all kinds of categories (e.g., animals, tableware). Each category consists of exemplars (e.g., snakes are animals), and exemplars have features (e.g., neck flaps). In an analytical mode, the mind will do just that: Look at the features and classify incoming data correctly. In a creative mode, however, the mind does not classify so much but rather makes connections across categories based on commonalities or distinctive features that are complementary (e.g., 'snake' plus 'spoon' makes 'cobra').

The computer program we made simply matched features between exemplars that were not in each other's categories. Note that the outcome is not just two words put together but two semantic fields that showed a fit conceptually: Apart from plain descriptors, "features" can be functionalities and experiences as well as cultural elements or "memes" (Dawkins, 1976/1989: 192). On the physical level, the computer was creative in making a conceptually fitting combination, except that the human designers optimized the combination (e.g., a spiral tail) to present it in a more acceptable form. Just like human creativity, physical creativity can come up with combinations that can be perceived by humans as novel after which humans may give meaning to that perception by generating more information (i.e. context) to make the combination acceptable (i.e. the spoon does not represent just a snake but a cobra snake): It is the human explanation in hindsight of the weird combination established physically (cf. Ward, Smith, \& Finke, 1999).

In establishing conceptual fit, coincidence also plays a role. This applies to all of nature, computers and humans included. In nature, novel combinations are established through coincidence and those findings are maintained through physical forces. DNA is nature's prime coincidental finding that appears to accelerate and optimize physical creativity. From this, the human mind evolved as a 
catalyst that accelerates and optimizes novel findings such that they are not based on coincidence alone. The human mind on its turn invented creative technologies that offer partially coincidental and partially deliberate creative findings. In other words, in nature organisms developed that accelerated coincidental creativity and from this, humans emerged as an extra accelerator that with creative technology accelerates its own acceleration of novel combination finding.

\subsection{Boundaries of creativity: From entropy to near-stability and back}

At the early stages of making a creation, when things are not combined together, the state of entropy or chaos of the information universe is higher than after the creative act. Creativity reconciles what was disparate at first. Because of this, entropy in the physical world is stabilizing over time. Single entities produce more complex structures, reducing the possibility of these primitive units to produce something different. Hence, the possibility becomes smaller that many different creations emerge. If a combination is formed, the component parts cannot be used in another way unless this new structure is broken down again (increasing entropy). If the new structure is to remain intact, the combination can merely be incorporated in yet another combination. This implies that the universal potential of creating something is decreasing over time. However, a complex structure has many more possibilities to interact with the environment surrounding it, which leads to an increase in the universal potential to create novel combinations. It might happen that these two forces of push and pull balance each other out and that the universal potential of creating remains in a steady state.

Based on the assumption of making novel combinations, the universal potential of creating something $(P)$ depends on the number of entities present in the information universe $(N)$ and the types of interactions (I) they may have among each other. For example, if the information universe consists of two entities $(A$ and $B)$ and these can interact with each other in only one possible way then only one creation is possible. Suppose that $A$ can only precede or be applied to $B$ then the possible creation is $A B$ (e.g., a spoon designed as a snake). However, if $B$ can also precede or be applied to $A$ then the universe has the potential of two creations, namely $A B$ and $B A$ (a live snake used as a spoon).

In Figure 1, the combination among entities snake $(A)$ and spoon $(B)$ in the information universe is not only based on common 'long' features but also on 'lean' and 'curved' ones. Therefore, the potential number of novel combinations is six ( $A$ long $B, A$ lean $B, A$ curved $B$, and vice versa). Hence, the potential of creation $P$ in this information universe is the product of the possible constellations that might come out of the permitted combinations of the entities $C(N)$ and the 
number of the permitted interactions types $I$. Over time, the number of single units that run free independently decreases due to the emergence of increasingly complex combinatory structures. On the one hand, this results into fewer possible combinations $C(N)$ that can be achieved in the future. Therefore, $P$ decreases. On the other hand, the new complex structures have more possibilities than the single units to interact with the environment. Hence, $P$ increases. It could be observed that the decrease in $P$, which is due to the reduction of possible types of combinations, is exponential. The increase in $P$, however, is linear as a result of the possible new interaction types that complex structures have. It thus follows, that in sum total $P$ decreases over time.

However, complex constellations of novel combinations have a tendency to internally rearrange component parts. If this leads to disassembling certain units, the complex structure disintegrates. This process may be instigated by a disruptive intrusion from the outside (e.g., bacteria entering plants). If it leads to reconnecting or making new connections within the system, the structure becomes more complex (bacteria in plants forming mitochondria). The increase in complexity mitigates the possibility for internal units of the structure to interact directly with information residing in the outside world so that by consequence, $P$ decreases. By contrast, disintegration of the complex structure releases internal units from their bonds so that $P$ increases. It thus follows that the development of $P$ describes a sinusoidal wave form, where $P$ decreases when complex structures are formed and increases when disintegration occurs over time (i.e. entropy). Of course, this process may not show a smooth sinusoidal curve, but what we mean here is that over time, $P$ keeps on shrinking (entropy decreasing, structure becomes more stable) and expanding (entropy increasing, structure becomes more instable).

The decrease in design space the more novel combinations are made does not merely count for physical objects. The demand of novelty certifies that combinations of ideas ( $A B$, snake+spoon) may be recombined with earlier ideas ( $A A B$, (cobra_snake)+spoon) but the newness of that higher-order combination of ideas decreases with the uptake of more of the same component parts (i.e. cobra as a specification of snake), decreasing the design space not of combination making per se but of novel combination making throughout. In other words, the leap between snake and spoon is larger than between cobra and snake_spoon. 


\subsection{The number of combinatory possibilities exceeds the observable universe}

In Figure 2, the left panel shows the initial state of an information universe that consists of eight single entities. These entities or information units float around freely (e.g., DNA scanner, mobile phone, cloud computing) and can connect and interact with each other in any possible combination to create new complex structures (e.g., mobile phone with DNA scanner connected to a data cloud). In the middle panel, five out of eight entities unite and together form a complex structure. The internal stability of this newly formed complex structure ties the five entities together and in doing so, reduces the possibility for each single entity to interact with the environment. As said, this reduces the overall universal potential of creation. On its turn, however, this newly established complex structure interacts with the environment as an entity of its own. This phenomenon represents the continuous line of creativity if from an external point of view the structure of this super entity remains stable or keeps on integrating single entities from the environment within its own self.

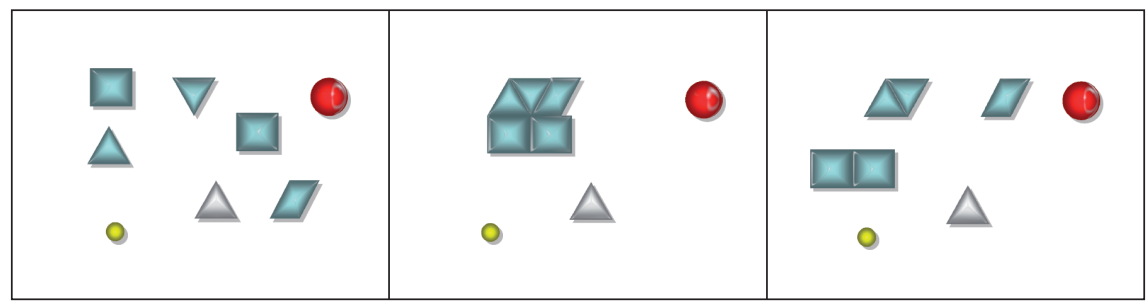

Figure 2. Information universe in various states: entropy, order, disintegration.

The right panel of Figure 2 shows a moment of disruption (i.e. crisis, error, or death) of the complex system. The structure disintegrates and internal component parts float around in the universe of information again, looking for new potential combinations, which increases $P$.

In addition, Figure 3 shows the change in external potential of universal creativity $P e$, the internal potential of universal creativity $P i$, and the total potential of creativity $P t$. $P e$ should be read as the potential of creation with the exclusion of the internal potential of each complex structure. $P i$ is the sum of potentials of creation within each complex structure, while $P t$ is the sum of total potentials of creation of the entire information universe:

$$
P t=P e+P i
$$


The graph depicted in Figure 3 shows the different potentials of creation as based on the information universe of Figure 2 but plotted on a logarithmic scale. In the beginning, at time point $1, P t$ and $P e$ are the same because all the entities are separated. On time point 2, 3, 4, and 5, entities start to combine and a complex structure of five sub-entities is established as one plus three independent entities. This increases $P i$, and decreases $P e$ and $P t$. At time point 6, the information universe seems stable but then a disruption happens, which disintegrates the complex combinatory structure into 2 and then 3 parts at time point 7 and 8 , respectively. $P i$ decreases whereas $P c$ and $P t$ increase. At time point 9 and 10 , the creative system is stable again. The panels in Figure 2 depict the information universe at time point 1 (left), 5-6 (middle), and 9-10 (right).

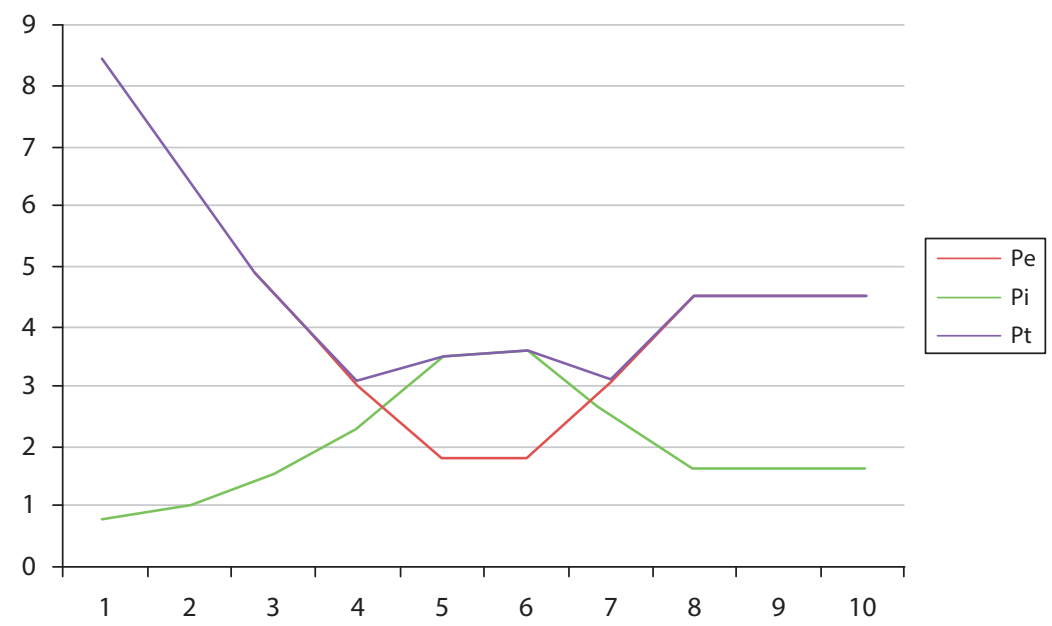

Figure 3. Relationship between $P e, P i$, and $P t$.

To formalize our notion of the universal potential of creating, that is $P$, the previous reasoning implies that $P$ is directly proportional to $C$ and $I$, hence:

$$
\begin{aligned}
& P \propto C \\
& P \propto I
\end{aligned}
$$

Combining these two statements results into:

$$
P \alpha C * I
$$

By introducing a constant of proportionality, we get:

$$
P=\eta * C * I
$$


Here, $P, C$, and $I$ are functions of the primitive number of units $N$ in the information universe at time $t$. In addition, $\eta$ is the constant of the universal potential of creating while $C(N)$ is the structural formulation of the $N$ number of entities that are combined with each other. The number of possible structural combinations that could be formed from $N$ single entities is exponential for $N$, indicating that the number of possible structures with $N$ single entities can accumulate to $2^{N(N-1) / 2}$. If an information universe comprises of as little as 50 single entities or information units, the potential number of structures that may be formed already is $2^{50(50-1) / 2}$. This potential number of making novel combinations is more than the estimated number of atoms $(280)$ in the observable universe.

This reasoning, a non-physicist might say, does not reckon with the psychological option that when one grouping in Figure 2 becomes 'old,' that same grouping can later on be viewed as new. For instance, Attridge (2004) posits that a work can still be regarded as 'creative' even when it is outdated and might be reiterated in the future (cf. simultaneous or repeated inventions). Personal creativity does not have to be as original as historic creativity - a first time invention ever (Boden, 1990), which not only the innovator but also society finds novel and surprising (cf. Kant's “exceptional originality," Attridge, 2004:36). Other forms, Attridge (2004:42-43) poses, remain innovative and surprising over very long periods of time no matter how ancient they are.

Indeed, novelty is relative to what one knows. As said, things might have occurred for the first time without someone noticing it or noticing it only much much later. If something unfashionable and forgotten is introduced as novelty again then psychologically it will count as new. From a physical perspective, then, the possible number of new combinations already may exceed the number of atoms in the universe, but psychologically that number can be even higher when one allows that older creative forms are recovered and reintroduced as novelty again in an uninformed community.

\subsection{Within the sinusoid boundaries: Fractal emergence}

Due to its combinatory nature, the pattern of interactions among entities or information units is nearly self-similar and definitely recursive. A combination of combinations consists of many component parts and usually shows more complicated behavior than if it were consisting of just one component (see previous section). This is particularly true when the components are allowed to interact (i.e. combine, recombine, and combine combinations). The combinatory pattern can then exhibit a behavior that is substantially different to, and cannot be predicted from, the summation of the behaviors of the individual components. This 
is referred to as "emergent behavior" and is a central concept in the relatively new field of "complexity" research (Casti, 1994).

Given that many natural systems feature vast numbers of interacting parts, the concepts of emergence and complexity have experienced spectacular success in explaining a diverse range of natural processes in the physical and life sciences (Casti, 1994). For example, when two liquids are mixed together, the chemical reactions between the elements in the liquids might induce an emergent behavior one that would never be observed in the liquids if they had been kept separate. This emergence can therefore be regarded as a creative process and the point at which it started as a point of disruption.

Such creative processes are not only observed in nature but in being a part of nature, in human behavior as well. Consider, for example, the emergence of a creative idea. Analogous to a collection of chemical elements, a room full of people might interact to generate novel thoughts that would not have emerged if the same set of people had worked in isolation. A similar idea can be applied to a single person. In this case, the thoughts themselves can be pictured as the component parts of the system. If these thoughts are allowed to interact in a combinatory way, then novel ideas and behavior can emerge.

The emergence behavior is creative only if it has not occurred previously. It is therefore necessary to define the information universe that the creative system covers. For example, consider the case of a family (which we label as family $A$ ) that exhibits a particular emergent behavior for the first time. If our system consists of only family $A$, then this emergent behavior is creative. However, if we extend our system to include two families (family $A$ and family $B$ ) and family $B$ has already exhibited the same emergent behavior, then the behavior of family $A$ is no longer creative in a strict statistical sense because it has been previously observed within the information universe under consideration. In other words, originality depends on sample size (cf. Hoorn, 2002).

We expect that the emergence process of creativity will follow a recognizable, generic pattern, limited only by the said sinusoidal boundaries of the creative potential $P$. A number of previously studied emergence processes have been understood in terms of the fractal geometry of nature. Fractals are shapes that repeat at increasingly fine magnifications and are prevalent throughout nature. For example, trees, rivers, and lightning have all been shown to be fractal (Mandelbrot, 1982). Fractals occur in temporal as well as spatial patterns. For example, the rise and fall of river levels trace out a fractal pattern with time. In both cases, the repeating patterns generate the rich complexity exhibited by nature. This repetition also generates scale-invariance. We therefore expect these properties - complexity and scale-invariance - to be generic properties of the emergence of creativity. Combinatory creativity is a fractal system because it guarantees an optimal search 
path through the information universe to find evolutionary niches and start a new line of development.

More specifically, search mechanisms appear to be a central part of the creative process, for example, when searching for the appropriate problem to be solved, or for out-of-category information to be used in solving that problem. A number of search processes in nature (including animals searching for food across a physical terrain and the human eye searching for visual information) have been shown to follow fractal patterns (Fairbanks \& Taylor, 2011). This fractal mechanism is a more efficient search mechanism than say a random approach to searching. We therefore expect the creative process to be driven by the emergence of a fractal search pattern. Much like a fractal tree, the emerging innovation lines will spread across the information universe or concept space in an interdisciplinary way, splitting along multiple branches of exploration.

We stress that our ideas of physical creativity provide a framework that can be applied to diverse systems of creation. In particular, our definition is equally applicable to systems consisting of conscious, intelligent components as to those that don't. Although the specific properties of the combinatory interactions between say chemical elements will obviously be very different to those between people, the underlying emergence principles of the two systems of creation will be the same. In particular, the number of elements in the system and the strength of the combinatory interaction between the elements will be important factors in determining the strength of the emergence for all systems of creation. Our model therefore views the creative process as a natural property of human behavior, and predicts that the likelihood of the creative process will increase with interactive collaboration. 


\section{CHAPTER 4}

\section{Perception as a limiter, perception as a fuser}

The current section discusses the role of perception in human creativity. As human beings, our take on the universe is not neutral. We are prepared to perceive the world such that it is most convenient to human goals and concerns. This way, data is reduced to categories that the human mind can deal with or needs, thus determining the cross-category combinations that potentially can be made, psychologically: One can be creative only with the information that is perceived. In addition, human perception has all kinds of distortions, which feed into the criteria with which novel combinations are evaluated and optimized.

During perception, entities become united or blended into a whole and sensations and ideas fuse intimately together. Given the information that enters cognition, perception is the first stage in combining things that on the physical level may function as isolated entities. Thus, perception is the transitionary station between neutral data floating freely in the information universe and the psychological creativity that works on those data. Perception is an important factor that stretches and bends the sinusoidal boundaries of the fractal emergence of combinatory creative search.

\subsection{Perceptual error: Making room for creativity}

If creative combination has a fractal element to it, then the combinatory system should allow for some noise or error. Perception plays a key role in the process of human creation as our behavior is constrained by perception. Our senses do not provide complete information about the world and therefore our perception consists of informed estimates and inferences (Helmholtz, 1969). Perception balances reliability and veridicality by relying on a combination of previous experience and incoming information. The visual system shows clear examples of how the universe observes its own creations via the human senses.

Our senses provide us access to the world with little effort so it seems. Yet information that our senses provide is both incomplete and unreliable. Perception does not end in the sensory organs; the nervous system has to do tremendous processing to arrive at a stable percept (Helmholtz, 1969). There are quite a few statistical challenges perceptual systems have to overcome. 
The sensory organs are all limited in the resolution and range with which they can register information. We do not hear tones above a certain threshold frequency and do not see ultraviolet light. And for the stimuli that we do register, resolution is high only in a small region of the range of the sensory organs. Try reading a newsletter from the corner of your eye and you will see nothing but grey blur. The quality of sensory information can be somewhat improved by explorative eye and hand movements, bringing a part of the world to the center of our sensory systems where resolution is best or by bringing the focus of attention to a region or a feature. However, improved resolution may come at the cost of selection, where other information is neglected (Paffen, Verstraten, \& Vidnyanszky, 2008).

Moreover, the information we receive is ambiguous: A signal registered by the sensory organs may have been the result of a variety of world events and a single world event may give rise to a variety of sensory signals. In other words, the mapping of world events to perceptual signals is not one to one (Marr, 1982). A rectangular window may be projected on the retinas of the eyes as a trapezoid or a square, depending on the viewpoint. And a rectangular projection on the retinas may be caused by various shapes in the environment.

Together, uncertainty and ambiguity allow for a range of interpretations from sensory signals. The fact that we perceive a stable and continuous world shows that the brain somehow selects a single solution, which we regard as 'true' or 'real', determining our window on the world (Hoorn, 2012: Chapter 1). In selecting a possible percept, the perceptual system must optimize reliability and veridicality. Unreliable perception, where interpretations change from moment to moment, interferes with the percept of a stable world. Incorrect interpretations interfere with successful interaction with the environment - successful relative to the organism's goals that is.

This problem of determining the cause of a combination of unreliable signals can be treated as a statistical problem of maximum likelihood estimation. Bayesian frameworks, which take into account perceptual experience as well as incoming sensory information, have been particularly effective in describing human perception (Landy, Maloney, Johnston, \& Young, 1995). In such a model, reliability can be increased by combining sensory information according to its reliability and by comparing information to an internal model of the likelihood that a stimulus will occur in the environment. This internal model of the environment, also called a prior, represents the frequency with which we have encountered a stimulus in the environment. For instance, we are able to interpret skewed angles as perspective deformations of a rectangular object because we know that rectangular angles occur more frequent in our environment (Gibson, 1966). We can thus select the most likely estimate by computing the statistical likelihoods from combined sensory data and previous experience. 
However, the most likely estimate is not always the interpretation that would be considered correct if we had complete information about the world, for instance, when a neighboring train departs and we have the illusion that our own train is moving. "Our own train is set into motion" is the most likely interpretation, because motion of an entire scene is more often caused by self-motion than by motion of the environment, yet it is the incorrect interpretation. To optimally interact with the environment, our sensory system cannot make too many of these mistakes and has to achieve a degree of veridicality.

We do not have direct information about the world. Our sensory systems only receive feedback on the veridicality of our sensory estimates by interacting with the world. To be able to learn from its actions, the nervous system predicts the sensory outcome of planned outcomes so that errors, or the differences between the predicted sensory state and the actual sensory input, can be computed (Wolpert, Ghahramani, \& Jordan, 1995). These errors can be used to update the internal model of the world we use to interpret sensory information. For instance, if we consistently end a bit leftward of where we planned to grasp a visual object, the nervous system may rotate its interpretation of visual information to correct for this leftward bias. In doing so the nervous system must decide whether an error is due to random noise or to a consistent error in the perceptual system. The nervous system does not have access to the veridicality of its perception and therefore makes best guesses optimizing both reliability (consistency) and veridicality.

\subsection{Epistemic considerations}

The problem that as humans we do not have access to the veridicality of our perception has broad philosophical implications. As a research group, our epistemic stance mingles two conflicting views. On the one hand we believe that there are events happening outside our observation and beyond our current language for which we might formulate natural laws, circumventing metaphor, myth, and everyday language "at all costs" (Pope, 2005: 173). On the other hand, we also acknowledge that what we can say about the world is susceptible to cultural norms and values - societal as well as scientific. Our account, then, embraces metaphor, ordinary language and scientific creational myth "precisely because these prove immediately accessible" (Pope, 2005: 173, also pp. 178-179).

Because humans try to optimize their perceptions to make them as reliable and veridical as possible, they will try to adapt their information filters such that all possible observations that are errors will not be selected as the actual observation. Theory and habit are instruments used by humans to improve perceptual reliability and veridicality. But these instruments may also have a negative 
effect on the veridicality of our perceptions, because not all interpretations that are rejected are at odds with experiences in the physical world (cf. Schrödinger, 1944/2010:163; Heisenberg, 1952:30). In other words, all errors are actually perceived errors, which are incorrect interpretations according to habit or theory. However, certain perceived errors will be taken for real errors in cases that the theory is regarded as almost infallible (Hoorn, 2012). The less someone adheres to theory, the more opportunities errors provide to serendipitously enter a new domain and be creative (cf. Torrance, 1988; Schank, 1988).

In view of some theory (e.g., logical empiricism), it may be that the most likely interpretation is not the correct interpretation of the world. Because we do not have full access to the physical world we can only determine errors by theories, which are based on previous experience. A theory may state that statement $X$ is true and statement $Y$ is false, for example that "the earth is flat" is true and "the earth is round" is false. A person who adheres to the theory of the flat earth will judge $X$ to be true and $Y$ to be false. However, there is the possibility of the person encountering a future experience that conflicts with the theory, in this specific case a ship sailing down the horizon, or a view of the earth as seen from the moon, supporting the judgment that in fact $X$ is false and $Y$ is true; a theoretical paradigm shift (cf. Kuhn, 1962).

If this person chooses to stick to the theory, s/he will most likely filter the conflicting experience out as an error and dismiss it. This will result in an observation that agrees with the theory, for example perceiving the ship sailing down the horizon as a sinking ship (or as a ship "falling off the edge of the earth"). This individual will be judged right by all other people that follow general theory. Although drawing a false conclusion, the system will come to a reliable conclusion. In summary, the fact that a possible observation does not agree with existing theory or habit will make it more difficult for the system to observe this conflicting experience as conflicting at all.

If however a more creative person is open to possible observations that conflict with general theory, s/he may take input into consideration that is so far from the range of possibilities specified by the current theory that $s /$ he rejects general theory and concludes that in fact $X$ is false and $Y$ is true. In this case (of course) other people who are less open than the creative person and who do follow general theory will tell the creative person wrong; that s/he makes an error.

The central point here is that sometimes it is necessary to be wrong (make errors according to general theory) in order to be more correct according to experience (which actually sustains just another theory). In the end it is more important (for example in a competitive sense) to be correct about the world as it appears to the senses than to be right according to theory: Sometimes it is necessary to trade theoretical reliability for momentary and goal-dependent 'veridicality.' 
However, our unreliable senses pose a dilemma: We cannot know whether conflicting information was due to an erroneous measurement by our senses or to an actual error in general theory (cf. Poincarés underdetermination thesis). We can only make our best possible guesses. To allow growing insight in the actual state of the world, it is important to (at least) be open to possibilities that seem to be errors according to general theory (cf. Miller, 2000:30 on Einstein); something which is generally perceived as an error, is not necessarily incorrect (cf. Miller, 2000: 84 on Galileo). This does not mean that in case of a conflict between experience and theory, theory is always incorrect; it simply means we have to be open to this possibility as well.

We argue that a creative person or system prefers adaptation to new information over the risk of making errors. Creative people or systems filter out information less rigorously and seriously contemplate alternatives (i.e. low stimulus discrimination). This means that they are capable of making what we might call 'double errors:' By happily making perceived errors, creative people correct errors that are 'real' according to general theory. A person or system that makes double errors apparently makes real errors in view of general theory or habit, but is correcting them in relation to an alternative hypothesis about the world. Creativity needs situations where world and theory are in conflict, because exactly these situations allow for a paradigm shift: A new way of looking at the world and of doing things. This implies that all creativity is a learning experience.

As said, there is a risk involved in being more open to perceptions or observations that conflict with convention. Increasing the probability of double errors also increases the probability of new 'real' errors, where new incorrect statements are accepted. There is no guarantee that nature is more likely to give us correct experiences than incorrect ones. Let us hope that chances are higher that truths that were previously perceived as errors will turn out to be genuine truths than that correctly perceived truths will suddenly turn out to be errors. In other words, incorrect observations (truths that are generally perceived as errors) hopefully are less stable than correct ones but eventually, there is no telling. The nature of our epistemics might be the reason that it is rewarding for a system - at least to a certain extent and at least some part of the time - to be creative so to escape conceptual fixity and adapt to change.

We have looked at the perception system in humans, where the sensory fusion and selection process produces our perception of reality. We also have seen that perceived errors might not be real errors at all because 'real' errors are a matter of theoretical bias. If the selection process filters out everything that we judge as useless, we arrive at perceptions to which we attribute a high level of trust (we only allow the seemingly reliable perceptions). This self-induced trust allows us to make split second decisions in case of critical situations in which our survival is 
at stake. This is a conservative and rigid approach, that allows for little to no new knowledge to enter the system. However, if the selection process allows for some less trustworthy alternatives, we have a much richer bouquet of perceptions. In return a more playful view of reality becomes possible, which allows for new ideas and knowledge to enter the system.

We do not know whether we have complete information about the physical world or not and while interacting with the environment, information that we consider new enters our system. Therefore, relying entirely on conservative and rigid selection criteria may constitute a problem in being maladapted to change. People habitually form theories based on incomplete evidence (Kirkham, 1984:512; Hoorn, 2012: Chapter 1). For instance, children assume that objects cannot disappear from sight without physically disappearing. They can resolve this occlusion problem only by adapting the theory that objects disappearing from sight may not have disappeared from physical reality (Piaget, 1952). If we do not adapt theory to incoming and evolving information, survival becomes sub optimal and favors those who can adapt to change by opening up their filters at least a little bit, tolerating new interpretations of information in support of a new theory. With new information and ideas, consequentially, new patterns can emerge. This ability to adapt to new information, can thus be seen as a prerequisite of our cognitive system to be creative in the first place.

Our perceptual system provides a window onto a physical world where we may observe or construe emerging relations and patterns. Because information provided by the senses is unreliable and incomplete (Schrödinger, 1944/2010:145), the perceptual system balances a conservative and efficient mode of processing with a more open approach (Hoorn, 2012: Chapter 6; also Csíkszentmihályi, 1996:11). The conservative mode relies largely on previous experience, which allows adaptation of perceptual theories. The liberal mode searches for new interpretations of incoming information. The latter is a more adaptive approach, which is open to detecting new patterns and relations for creative use. From the conservative perspective, it is also the more risky approach because it tolerates unreliable data and perceptual errors - according to general theory that is. As creativity may come at the expense of conventional reliability, creativity may demand conditions in which our perceptual system can survive with a lower degree of reliability and is allowed or even stimulated to open up its perceptual filters.

This possibility is certainly speculative and may be investigated in experiments that bridge the fields of social psychology and psychophysics, where perceptual reliability is measured in settings that have been labeled as creative or non-creative. When new interpretations are allowed, the potential benefits of the breakthrough reach beyond the moment, as it instigates an incremental process 
where the new interpretation may allow the formulation of new theories, which in themselves contain sufficient noise to allow for new breakthrough interpretations based on error, and so on. This is how human creativity unfolds.

\subsection{Language and signs}

"Our world is what we say it is" (Bois, 1972). A bold statement like this is understandable once we come to realize how much our senses and our brains limit and modulate the information we work with. We come from perception and nervous systems of people are not different across different language populations although the way they categorize their impressions is (St. Clair, 2002).

Categories are phenomenological. They reflect the perceptual structure of the perceiver. Even though categories harbor prototypes, what constitutes a prototype is usually culturally defined.

(St. Clair, 2002)

In other words, what we say about the world is how we frame it. How we frame a problem guides its solution (e.g., Kahneman \& Tversky, 1984). A creative solution, then, is affected by the way the problem is represented, whether by images or by words.

Perception modalities filter what information is available (cf. Elsom-Cook, 2001:3-6). Sight, hearing, touch, taste, smell (the senses) but also the channel, the form of encoding within a modality (or sense) does that (ibid.), such as speaking a specific language (auditory) or using infographics, icons, and printed texts (visual) (ibid.). A medium is a set of coordinated channels across one or more modalities (e.g., speaking different languages - acoustics - gestures - visuals). Such combination of channels is conventionally regarded as a whole (e.g., the explanation of sign language to hearing people) with a coherent interpretation across channels (i.e. the spoken language should mean the same as the gestures) (Elsom-Cook, 2001:3-6).

Words are conventional definitions; otherwise communication through symbolic interaction would not be possible. In creativity, this is exactly not the case: Creativity confuses modalities (e.g., synesthesia), breaks with the conventional definitions of the channel (e.g., neologisms), hybridizes the medium (e.g., interactive TV), and prompts ambiguous interpretations (cf. literary exegesis). For normal communication, the convention is maintained that a sign (e.g., the word "cat") refers to the right internal concept (e.g., a prototypical cat) as well as to the proper entity in the external world (i.e. the actual cat outside) (Carter \& Knight, 2008). ${ }^{7}$ These relations are derailed by creativity: The sign that belongs 
to the concept can be altered or vice versa, the concept is changed that belongs to the sign. For instance, the generic word "cat" is replaced by "fireplace rugs." The thing that the sign refers to changes or sometimes the sign to the thing: Since the 1950s, the word "cat" may also refer to male rock'n'roll devotees. Or the relation between the internal concept and the thing in the external world is distorted: A different prototype describing the same external thing or different things that alter the semantic coverage of the prototype. For example, the notion of the prototypical domestic carnivore is extended with atypical forms such as Sphynx cats or the Cheshire cat.

Therefore, human creativity is a communal act. The interpretation of the newly formed sign is as important as forming the new sign itself. For Attridge (2004:33,102), interpretation is relating novelty and difference to the self and its surprise effect constitutes the co-creation of meaning. This position is in sharp contrast to New Critics as well as Postmodernist literary theory, stating that a text stands on its own without a social context. It may even be so that a work is valued for different reasons over time, which according to Attridge (2004:67), is a characteristic of all semiotic singularity.

In linguistic research on creativity, an "externalist view" exists that assumes creativity as outside the standard language. So called "internalists" see creativity as fundamental to all language use (De Beaugrande, 1978). Carter (2004) sees creativity in the subtle novelties of common speech and not only in written text such as formal language or literature. Similar ideas are found in Pope (2005) and Pope and Swann (2011:11); less so Attridge (2004). Linguistic creativity relies on recombination (De Beaugrande, 1978); on new forms materializing in combinations within or among linguistic systems (ibid.).

Externalists see creativity as deliberate and contemplated (cf. romantic disruption) whereas internalists emphasize that novelties 'just happen' while you are talking (cf. serendipity). Earlier, we have discerned a physical mode of creativity from organic creativity and stated that human creativity is physical in part. The internalist view comes closest to our understanding of physical creativity. Physical creativity cannot be avoided; it just happens because features of different entities look similar or are complementary. Physical creativity can be repressed, however, for example, when the mind is not empty of thoughts (cf. 'mindfulness') and each impression needs to be named, labeled, categorized, and articulated (cf. ontological classification in Hoorn, 2012). In early creation, non-verbal modes of thinking are important (e.g., Gruber \& Davis, 1988) and words get in the way (cf. Simonton, 1988:397). The externalist view comes close to what we regard as organic creativity. It is more evaluative and aware of standards and criteria so to deviate from them deliberately and, for example, 'create art' or 'do science.' Words enter after associative play comes to ease (Simonton, 1988:397). 
Because they are conventions, words (or signs) have more-or-less fixed relationships with internal concepts, which are prototypes and stereotypes. Without much empirical experience or knowledge of the world, words can obfuscate what is distinctive between the prototype in our heads and the things in the physical world that we believe are exemplified by the prototype. Words generalize over phenomena so that details are missed that might connect. The prototype of one class may differ widely from that of another class. Yet, exemplars peripheral to their own class may show similarities and complementarities that bridge the categorization gap. Such opportunities for novel combinations are easily overlooked by merely thinking in terms of prototypical exemplars.

Words also may be beneficial to creativity. What seems playful language at first may later serve as a signpost to new knowledge domains or novel expressions forms. Chomsky $(1966: 41,59)$ sees generative creativity as a finite stock of structures in a homogeneous speech community that applies known computational procedures to make and understand various utterances. Zawada (2006) does not agree to this view as it cannot account for the generation of novel meanings or new grammatical constructions beyond the system. Creative language shows complicated and communal forms of wordplay (Carter, 2004:6). As Zawada (2006) illustrates, word creation follows real-life changes (e.g., "yuppification") or tries to make aspects psychologically salient (e.g., devilicious combines devil with delicious). Language creativity also reflects the values and standpoints of its speakers and listeners (Pope \& Swann, 2011:17).

Creativity depends on drawing in new information to make a unique crossover at the flash of insight (e.g., Gardner, 1988; Torrance, 1988). This may be done via perceptual error (previous section) but the trick also may be done by word associations as employed in Apollinaire's automatic writing or Joyce's interior monologues. All these techniques bring about meaning relationships that were previously held for unthinkable or inaccessible. Through the use of metaphor, simile, neologisms, or idiom variations (cf. Pope \& Swann, 2011:12-14), similarity between non-adjacent domains can be indicated and retrieved. Stylistic devices such as metaphor may even encourage new grammar or linguistic conventions. Heine (1997:8) offers the example that a literal utterance such as "They keep the money" (Subject-Verb-Object) when taken metaphorically leads to new grammar: "They keep complaining" (Subject-Verb-Verb). Metaphors empower a rich and rapid understanding of new ideas (Ryland, 2011). Metonyms or 'part-forwhole relations' are domain-internal ways to expand meaning, using proximity and adjacency to draw in meaning (ibid.). Idiom variation takes place through 
semantic extension (Langlotz, 2006). Many of these semantic variation principles boil down to combinatory creativity and sharing feature sets (ibid). 8

The organic side of human creativity is more evaluative and analytic (cf. the externalist view). It selects and adapts the novel ideas such that they fit the goals and concerns of the creator and the group s/he belongs to. At this stage, language is most convenient. Abstracting, reasoning, and evaluation are done best in text and speech. For that matter, repetition across speaking turns is not merely echoing language patterns but rather a type of conversational gameplay (Carter, 2004:7-8). The transference of novel ideas to members of the community obviously benefits from symbolic communication. This is most advantageous in cocreation, where meanings have to be negotiated throughout the entire creative process and an 'affective convergence or commonality of viewpoint' is to be found (Carter, 2004: 8).

8. http://www.idiomatic-creativity.ch/Appendix\%20B.pdf 


\section{CHAPTER 5}

\section{Human creativity}

We stated that creativity is the unique combination of previously unrelated entities, which may coincidentally happen in inorganic as well as organic nature and which more purposefully happens in organisms, humans being the pinnacle as yet. In opposition to an organism, a stone does not fight for survival and does not care whether the right sort of molecule is at the right place in a given structure. An organism fights for just that. The stone is not interested in maintaining its structure and when threatened does not evade to uncharted terrain. The difference between the stone and the animal is that the stone has no goals. The animal does and so do plants. An animal is conservative about its constitution and only in crisis, will jump to another plane and becomes a scavenger instead of a herbivore or becomes a predator instead of a scavenger. An organism is a theory about the world - about which combinations of matter work as a self-replicating system - put on trial and tested by a world that is continuously changing. Each individual organism is a specific derivation of the theory, a hypothesis if you will, that when it is eaten before it replicates indicates that the hypothesis failed and that the theory may not be sophisticated enough. When the species dies out, the theory is refuted. When the species changes and conquers another domain (e.g., lizards conquered the skies and became birds), the theory still holds albeit in adaptation. Human creativity bears the same function. It is the ultimate escape to new feeding grounds when business-as-usual is on the brink of fossilizing. And it does that on purpose, not only by accident.

The disruptive leap is a phase transition, the evolutionary search for small niches is fractal. Bigger and smaller errors (i.e. chaos) provide opportunities to escape from general theory and search for unoccupied spaces. This is a most effective approach as the number of possible combinations outweighs the estimated number of atoms in the observable universe. Playfulness is a human search algorithm for ultimate survival.

Hence, human creativity on the one hand encompasses the physical process of combining entities on the basis of similarities and complementarities and on the other hand, the purposeful elaboration of the novel combination in terms of selecting, adapting, and integrating the entities such that they fit the (conglomerate of) goals best. The physical combination is expansive and disruptive, the organic incrementation is conservative and evolutionary. This divide also 
predicts that there is a stressor continuum: Too little stress brings laziness to the organic side of creativity, so that new ideas are not optimized for specific purposes. Too much stress leads to paralysis and a narrow focus on the details (survival thinking), leaving no room for the physical process to associate across fixed boundaries.

This theoretical stance explains many of the phenomena observed in (scientific) reflections on creativity. We saw that each individual slightly differs from general theory. Therefore, the organic aspect of creativity is not only goal-driven but viewpoint dependent as well. This makes a creation context-specific in the sense that it depends on the environmental circumstances, on the information the creator as a perceiver has access to, and on the goals the creator wishes to attain. ${ }^{9}$ It also depends on the perceptions and goals of the viewer or listener. In other words, the receiver is the co-creator in the manner in which he or she perceives the creative message or product. The output of the creative act is every bit as important as the concept in the creator's head. It is not an individual process - as soon as creativity is observed, it is in interaction with the observer. Thus, it is the juxtaposition of the apparently incongruous perceptions that truly defines a human act as creative.

On the organic or psychological side of creativity, the creator is attuned to the receiver to anticipate his or her reactions. The response that the creative output evokes in the receiver then may be intentional - as will often be the case in human creativity - but does not have to when the creator "regresses" to the physical side alone. Ecriture automatique as rediscovered by André Breton in 1919 or the work of serialist painters such as Sol LeWitt hardly have any clear intentions as to what it wants to stir in the receiver. More extremely, machine creativity or the wonders of nature do not have any intentions at all, they do not intend, they exist. And yet, in the mind of the receiver who is the co-creator, these poems, paintings, fractal graphics, musical pieces based on genetic algorithms, flowers, crystals, and birds, do acquire meaning and arouse feelings of aesthetics and astonishment.

Of course, then, there are environments and social mechanisms that foster and nurture creativity and bursts of enlightenment - for creator and perceiver alike. Drawing more and more diverse information into the equation stimulates the occurrence of wild jumps. The advantages of allowing new interpretations into our system go beyond merely being able to adapt our theories of reality. Allowing new information into our system gives rise to concepts like 'playing' and 'dreaming, both used to project (expression, music), simulate a situation (fiction, reflection), simulate a possible future (science fiction, "what if" experiments),

9. The process of designing goals is as creative as the design of means. Probably more products fail because of a defective design of goals than of means (Poelman, 2005). 
and learn new skills. In fact, one of the most important trends in the development of science and technology may be that these frequently bring to view physical aspects of reality that were previously unnoticed or unknown.

Most beneficial in this respect is a culture of awareness and openness of people, of diversity of thought, with people that have the ability to see the separate pieces (so that they can later be assembled), that have the opportunity to look into the ideas of others. The reverse is also true. An art school or research group that is self-occupied and does not allow outsiders to partake in their activities is bound to stagnate and repeat itself. A creative ecosystem is built on trust and safety so that bare survival is not at stake and the physical process of making unique combinations blooms. To be able to take risks and find unexpected opportunities, there should be a license to fail and cheerfulness in making errors. To stimulate the wild ideas happening, the attitude should be one of hope and of a positive outlook, of boldness of thought, flexible, dreamy, and the pleasure of play for its own sake.

\subsection{Playfulness}

As said, the optimization and incremental side of creation is organic and the organism is directed at optimal functioning within a given environment ("survival"). That is why the incremental side of creativity is more rational, smart, or intelligent if you will. It brings the sudden jump back to what psychologically is perceived as "reality." It is more serious in that it adapts the sudden insight to the rules of the game and takes into consideration all kinds of environmental restrictions, social and cultural norms and criteria (cf. Csíkszentmihályi, 1988; Gardner, 1988; Hennessey \& Amabile, 1988; Gruber \& Davis, 1988 in Sternberg's (1988) The nature of creativity). The jump to another domain, the sudden insight, is free from all that. Physics does not think but happens. In other words, apart from being rational, you need to be playful. Change the game, just for the fun of it.

The creative act itself is enjoyable. We lose ourselves within this creative act by indulging in our thoughts and curiosities, leading to the dissolution of lines between "working self" (the controlled organic part) and "playing self" (the uncontrolled physical part). This can look different for different people: Creativity is not always about producing a great work of art or a new theory. These are two types of creativity - some people lose themselves within doing business or policymaking - it is dependent upon the values and desires of the individual.

Creativity as playfulness is at odds with power play. It is not economic but rather subversive (cf. Pope, 2005:27). Consolidation of a power position starts with rules, regulations, control, and management. It tries to maintain the 
circumstances under which the organism perceives it lives optimally. Yet, the degree of regulation is inversely related to the occurrence of playful behaviors. When you begin taking yourself and your position too seriously, behaviors can no longer be playful. Creativity starts with feeling an appropriate lack of seriousness. Creativity is a version of joyful reflection instead of a working and obligatory reflection (which often is deprived of joy). The concept of "work" by definition is built upon the idea of obligatory expenditure of energy in a fixed setting. That is not to say that people cannot find joy or play in their work. In fact, people can truly meet the concept of self-actualization when there is full alignment between work and play. Play as an attitude toward work pushes someone to their most creative - when they are playing and engaging with the material. One can take playfulness as serious - the topic of the work can be serious, but the approach to it can be one of enjoyment.

As with power and control, one cannot harvest true creativity to reach economic goals - creativity comes from internal motivation (i.e. the unstoppable physical process) not from external rewards (i.e. the optimization for survival by the organism). There may, of course, coincidentally happen to be lucrative outcomes. However, true creativity is not inspired by economic greed or external gratifications. If a true goal (or some end) is already set, you may miss out on the best ideas because the focus becomes too narrow. There is no hidden agenda behind play - the physical side is truly independent. Creativity flourishes because of its freedom - it is intrinsic because of what it is, a physical process of combining entities in a new way. Against the conservatism of the organism in survival mode, it takes risks because it does not see purpose or goals and therefore does not know what risk is. It just is. For the genuine creator, it is okay to try new things because $\mathrm{s} /$ he hardly knows what risk is. There is merely joy. $\mathrm{S} /$ he is more into contact with her physical being than with her organic or psychological self. The creator is not looking for a creative outcome, it happens - you move forward with it and you do not know where it ends (or really how exactly it began).

Therefore, play does not need a tangible end product. Play becomes work when at the end of the day, having completed a series of tasks is all that matters, without attention to deriving joy or pleasure from those tasks. "Play" does not imply "silly" - rather, "pleasure" and "enjoyment" and "exploratory" and "discovery." It is an unspecific search. Creating new problems is almost as enjoyable as creating solutions. Grafted on the Dutch word "verwondering," playfulness coincides with "furtherwondering," wondering beyond the known, always looking for the next question. 


\section{CHAPTER 6}

\section{Implications}

\subsection{Holistic model}

We devised a consistent holistic model of creativity that has two layers. Creativity is inherent in nature's structures and processes on a physical level: Through the ongoing combination of combinations into previously non-existent larger units, the universe cannot be but creative. The creativity of the physical system has produced a new, organic, system: plants, animals, people, and ultimately human cognition. Due to its physical undercurrent, this organic system also is inherently creative.

The organic side of human creativity minimizes coincidence, which is the driver of creativity at the physical level. As a result, people are able to accelerate the creative processes that take place at the physical level. However, human creativity has yielded yet another layer: technology. This layer also provides opportunities to accelerate creativity, by minimizing chance and systematically exploring the information universe or 'search space.' Thus, creativity is not so much a choice as it is the way the universe progresses and the core of everything that the universe produces. The choice for humanity is not whether to use creativity, but how.

Now that we have concluded that creativity may be a unifying element in the physical, organic, social, and technological domain, the next question is how creativity unfolds at various levels - more probabilistically at the physical level and more deterministically at the organic. It is our expectation that understanding how creativity develops at every level will help us understand how law-like creativity is in general. When we get there, we have something very powerful in our hands.

One of the human moderators of unbound physical creativity is the demand of quality. Another is morality. The organism asks for sustenance of its structures and processes and so provides a deterministic edge to unbridled innovation, imposing rules and regulations that guarantee sufficient continuity of a chosen innovation line, including the preservation of the self. Through humans, the universe becomes more deterministic over time.

Romantic folk theory has it that creativity is something new that comes out of nothing: The creative genius would be a person who out of some sort of madness or else divine intervention conjures up the sublime (Pope, 2005:76, 103). “... the 
hyper-individualistic notion of solitary genius the lone artist in his garret or the isolated scientist slaving away in his laboratory" (Pope, 2005:66). If it is not so that creation is from nothing (ex nihilo) but rather from something else (ex aliis), are we merely talking about re-creation then (Pope \& Swann, 2011:9-10)? Not quite. We now know that at all levels the nucleus of creativity is a compound of two or more parts, which can be fused into one new unit. The amount of 'genius' coincides with the size of the associative leap between component parts. This is a judgment in hindsight which is goal and viewpoint dependent. Not everybody called a genius is acknowledged as such by each individual and on the plane of physical creativity, no judgments exist. The physical universe is untouched by genius, quality, or morality unless humans impose that upon it. Creativity arises where entities that seem incompatible, but apparently were not, fuse into something entirely new. This may happen during nuclear fusion but also in cases of biological mutation as well as in humor and art.

A key factor that drives creativity is chance, coincidence, or probability. The more creativity is molded by the human organic system, the smaller the role of probability becomes but it will never be absent. Not only does the theory of evolution show combinations of determinism (i.e. selective retention) and probability (i.e. blind variation), at a very practical level also quality assurance and risk control are managerial demands meant to ban out coincidence. The main reason why creativity often is not appreciated is that it does not match the current prevailing desire for control and efficiency. Simultaneously, books that discuss 'tipping points' and 'serendipity' in business and governance (e.g., Gladwell, 2002) indicate a great need for demystification of creativity just to get a grip on it and get rid of coincidence. From our perspective on creativity, we now know that this is the same as trying to ban gravity from the earth. It would be much wiser to breed diversity and tolerance for lucky chances to strike and to develop theory (e.g., fractality) that helps to explore this great potential at an extremely fast pace.

\subsection{Creativity in all, creativity for all}

Creativity as we define it is independent of person or time. Because it is inherent in nature and something that cannot be suppressed (although many political systems tried to), all matter has and thus, all people have the potential to be creative. In the wake of the Western "Age of Reason," creativity was banned to a special realm of arts and design while attempting to exclude it from serious matters such as science, business, governance, technology, education, religion, or politics. And where it could not be avoided or suppressed, creativity was markedly bound by time (e.g., brainstorm session, carnival, leisure time, hobby) and placed in limited 
spaces, such as laboratories, studios, workshops, or kindergarten. Or, in the wake of that other defining period of the West, Romanticism restricted creativity to specially gifted individuals; the genius waiting for inspiration and superior insight. The interpretation of divine creativity of which certain humans are merely the humble instrument made creativity a mysterious process in which only a happy few were blessed as the chosen ones. In other words, creativity was treated as either ludicrous (the rationalist view) or sacred (the romantic view).

By the turn of the 20th century, the idea gained influence that creativity resides in all humans. Freud believed that from the unconscious, creativity determined our behaviors in pursuit of pleasure and avoidance of pain (e.g., Freud, 1986:44-46). In the vein of Schiller, Freud developed the thought that artistic or literary creativity arises when ratio does not suppress the imagination and fantasies can run free. As such, creativity would be the work of the unconsciousness, free from rational limitations or the demands of ego (ibid.). With Freud, the Surrealists declared all people to be artists because of their ability of free association and the spontaneous generation of ideas (cf. automatic writing). During the 1970s, Joseph Beuys proclaimed that everybody was an artist ('jeder Mensch ein Künstler') (Von Graevenitz, 2009:266), challenging the postwar emotional oppression of humanity. The modernist context of the 20th century tried hard to liberate creativity from contributing to ego, truth, or utopia (e.g., Kris, 1952; Kubie, 1958, both cited in Arieti, 1976). Postmodern thinking made us aware of circumstantial and subjective interpretations: We as humans interpret our context in the light of our personal circumstances and history (e.g., Bellak, 1958, cited in Taylor, 1988). Those interpretations are influenced by cultural, social, economic or political beliefs and experiences. In such a highly subjective and contextual idea of humanity, human creativity cannot be separated from the human condition: When all interpretations are circumstantial, so is playing with these interpretations.

This perspectivism and subjectivity of postmodernism gave way to the multitude of coexisting interpretations of the same information, facilitating the combination of disparate strands of knowledge into a novel vision. Only in contrast to a diversity of interpretations, can the authenticity or originality of thoughts become visible. So yes, creativity is a personal quality of playing with interpretations and perceptions of the familiar, but this quality is non-exclusive and part of us all: “... creativity is not simply a property of exceptional people but an exceptional property of all people" (Carter, 2004: 13).

Currently, this trend is sustained by the rapid spread of ideas through the Internet and a do-it-yourself mentality that produces concepts of creativity that are void of exclusivity (e.g., Van Abel et al., 2011). We become - almost in spite of ourselves - creative because we experience how each on our own we construct our individual interpretations that are then confronted with those of many others. 
The relativity of truth that transpires from all those interpretations and perceptions (or "perhapsions" if you will) force us to develop new ways of conduct and manners. The "otherness of the others" becomes an important production factor in the construal of novel interpretations. The information universe expands: Celebrate the differences!

As a case in point, Fablabs crop up around the globe as they share the philosophy of (part-time) free access to facilities (e.g., laser cutters and 3D printers). In return, Fablabs ask that the users document their productions, enabling the reproduction, personalization, and improvement by others around the world. This approach stimulates an Open Hardware, or Open Design ecology, generating a multitude of designs (e.g., Van Dijk et al., 2011; Avital, \& Téeni, 2009). At the same time, it revitalizes the concept of the craftsman (Sennet, 2008), leading to vibrant crowds that use platforms such as Instructables, ${ }^{10}$ Make Magazine, ${ }^{11}$ and Etsy. ${ }^{12}$ Lastly, the Fablab approach is a driver for Design Thinking (Brown, 2008) as a complement to traditional educational systems.

Design Thinking promotes the use of design practices and attitudes such as openness and curiosity while focusing on collaborative practices of making, tinkering, sketching, drawing, and materializing solutions. Design Thinking believes that by working with your hands, bypassing rational thought, intuition may lead to breakthroughs. From low-tech 'paper-based prototypes' to high-tech fully functional applications, designs are tested and refined with large user groups, leading to actual products and services.

Those who think that co-creation approaches to innovation result in nothing but incremental or evolutionary designs; the impact of collaborative work may be just as high as the work of the specialist creator: Fablabs produced city plans for the revitalization of run-down boroughs, networked toys that foster social connections, ${ }^{13}$ open Wi-Fi antennas that can distribute the Internet across rural areas, ${ }^{14}$ and 50 dollar lower-leg prostheses for the developing countries (Schaub et al., 2011).

10. http://www.instructables.com/

11. http://en.wikipedia.org/wiki/Make_(magazine)

12. http://www.etsy.com/

13. http://www.waag.org/project/scottie

14. http://fabfi.fablab.af/ 


\subsection{Implications for human cognition}

The previous section argued that creativity thrives when it is human-oriented and empathetic (vs. product oriented), has an integrated approach (as opposed to focusing on specific elements of a system), is done in interdisciplinary cooperation (vs. a waterfall process), has iterative development (to build is to learn vs. first specify and then build), and switches between divergence/convergence and exploration/specification.

From a psychological perspective, a mentality is required of optimism, experimentation, exploration, collaboration, co-creation, of being pragmatic, flexible, and inventive. Within this way of thinking and working, there are implications for human cognition when it employs perceptual information in, for example, reasoning, social interaction, and future-oriented behavior (e.g., the design of scenarios). When perspectivism is a prerequisite of being creative, what are the advantages or disadvantages of allowing new (and possibly wrong) information into our system? The new information could be plainly wrong, and we could end up reacting in an erroneous and potentially life-threatening way, not only for ourselves, but also for others. We could waste our time and do something that makes no sense. We could insult or even harm other people. We could upset the social structure. But then again, old theory could be based on plainly wrong information as well, and be just as abusive and offensive.

In many creative social settings, people allow themselves and each other to take the risks involved in exploring uncharted territory. Creative settings may decrease the need to be fast and reliable and may create the conditions that nurture the opening up of the selection filters. Creative settings are open (allowing for wider ranges of perception), provocative (challenging existing habits or theory), inspiring (distributing a diversity of ideas and theories), and non-judgmental (failing is not immediately rejected). Creative social settings also encourage a level of trust. They control the damage that might result from a potentially harmful action.

The advantages of allowing new interpretations into our system go beyond merely being able to adapt our theories of reality. Encountering new information invites playing and imagining. It leads to new expression forms, contemplating future scenarios, simulating situations, and learning new skills. Science and technology bring to light aspects of reality that were previously ignored (Von Bertalanffy, 1968:242). Science, by challenging established paradigms and proposing new theoretical approaches, allows researchers to see beyond a particular framework. In this way, aspects of reality that were previously neglected become relevant and potentially predictable, explained and understood. When we use new 
information to select and design tools, such when taking the observation that light direction can be transformed through prisms to create a magnifier, we can start an incremental process where more and more information can be gathered.

Technological advances bring us 'artificial sense-organs' that allow us to go beyond the constraints of physical human perception and expand the limits of what is observable in the world, and the structures of the environment that humans interact with. This trend is cumulative and accelerates over time, as newly observed realms open possibilities for novel observations, and so on. Von Bertalanffy (1968:244) lamented that this state of affairs while desirable for research progress, also may bring about a de-anthromorphization of science (particularly in the 'exact' sciences), where human emotion and experience barely play a role. Nowadays, however, the re-humanization of science and technology is a current concern of philosophy and social science. Researchers like Clark (2003) and Latour (2007), have made us reconsider the way we think about artifacts and the ways in which artifacts influence and even change our human condition (see previous section).

We think it important to be aware of the continuous presence and impact of technology in our world, and that it may be a positive step to embrace it. After all, by allowing humans to expand their perceptive potential, science and technology constantly provide new opportunities for human experience and creativity. Creativity, that is being open to 'errors' in perception, might in turn very well be our most valuable human tool in dealing with a changing world.

\subsection{A double consciousness: Implications for the concept of self}

In our view, physical creativity is active outside but also inside the organism. Therefore, there is not a clear distinction between the self that is creative and the context or universe in which it is creative. On the one hand, this gives humans access to places in the universe which they would not be able to access if they were separated: It makes the disruptive leap possible. On the other hand, it conditions the options of choice since people are determined by their context: They work on continuation of an evolutionary lineage while perception limits the data they can access. Errors are actually a way to bypass the limitations of the cognitive and perceptual systems and open up to physical creativity again.

As said, human creativity includes a self-conscious feedback loop as nature looks back upon itself. To a certain degree, the creator needs to understand what $\mathrm{s} /$ he is doing to understand how to be creative - s/he needs to know how to play around. Play has a double aspect in that one is absorbed by it (the physical, 
unconscious, process) while being aware of the play itself and adapting it (the psychological, more conscious, process). It is putting oneself inside and outside 'the magic circle' at the same time.

The consequences of this double layer of physical, unconscious, creativity and organic, more conscious, creativity is that you can play with the intentions of a set of rules. In sports, for example, you could have a computer design a sports field based on similarities with other sports fields without any relationship to the rules of the game. Then give those designs to people and let them create rules based on that particular field (cf. Ward, Smith, \& Finke, 1999). First define the field, and then define the play. The same idea could be followed in education: The students could invent the learning space without knowing anything about pedagogy (cf. the airplane classroom $)^{15}$ and then the teachers make up the educational contents and rules that go with this new type of classroom.

The physical 'jumpy' side of creativity is directed to the materials - it is the absorbed creator in unconscious communication with the matter. The organic 'optimization' side is directed to the community - it is the creator as a social creature in conscious communication with other people (cf. 'the field' in Csíkszentmihályi, 1996:27-33). Creators who are focused on matter alone and who hardly comply with the rules and norms of a social group will be easily misunderstood in spite of their brilliance. Those being fully aware of others while creating will be highly successful in spite of their sometimes mundane ideas.

\subsection{Autonomous creativity and ethical restrictions}

Creativity is only rational in part (i.e. the organic aspect) and its unconscious and more-or-less disruptive nature may lead to unexpected successes (e.g., nuclear power) but to disastrous contingencies as well (e.g., nuclear waste). New products, systems, and services may be developed based on research but also researchers cannot be aware of all the implications of the fruits of creativity. Due to conceptual biases (cf. cognition) or measurement flaws (cf. perception), important consequences may be overlooked.

Moreover, if part of the creative process is inherent in nature and therefore cannot be completely and consciously controlled by an organism, in how far then are creators responsible for the negative consequences of their work? It is a question that comes up more and more in circles of designers and engineers. ${ }^{16}$ Many

15. http://thekingswings.com/index.php?page=blog

16. http://www.o2.org/index.php 
design schools have introduced the ethics of creation as a basic subject. ${ }^{17}$ Several companies as well as the European Committee have introduced special laws of liability into the product chain. ${ }^{18}$

The universal mechanism of creativity is of a combinatory nature. In human creativity, entities are described by certain features and combined through the similarity with or complementarity of features of earlier-on unassociated other entities. Because the search light is on commonality, features that do not contribute to the enhancement of the newly established sameness are ignored (cf. Runco and Sakamoto, 1999:68). If we translate the features that establish novel similarities to 'knowledge items' (Poelman, 2005), which are the things we supposedly know about the entities, then it might well be that ordinary distinctive knowledge items are discarded at the cost of unusual and exciting new connections. As creative as may be, the new combination may be void of down-to-earth common wisdom of 'how stuff works' and why things do not match. In industrial design, one often sees that creative students do have the skills to associate but lack the availability of knowledge items. Certain students are able to generate a host of ideas but the quality of those ideas is often poor because of the limited amount of ad hoc knowledge: They do not know what they are talking about and the design is mere fantasy or wholly irresponsible. In comparison, a tennis player may invent all kinds of new techniques and strokes but with a limited mastery of the known types of strokes, s/he never will become the world champion.

Of course, people have limited knowledge, which for a large part is determined by the social environment. Because creative acts combine knowledge items from disparate origin, they affect not just one but a multitude of social environments, which inevitably leads to "partial rationality." Would this then also lead to "partial liability" - you could have known but only so far?

\subsubsection{The dogma of novelty}

We argued that the organic incremental refinement of a disruptive idea is the more conservative part of the creative process, whereas the sudden jump is the search for newness. According to Poelman (2005), always being alert on alternatives is not per definition a human property; it has grown since the enlightenment era. Because of rationalization and industrialization people were capable to satisfy their basic survival needs, from which they could try and reach further. 
To date, the word "new" seems to continuously gain importance and is regarded as a recommendation of itself. We live in an era in which the existing is just the starting point of new things to come. This longing for the future, away from the here and now, is visible by a "systematic searching" for the new, through human heuristics or machine computation. One could pose that the unconscious part of creativity cannot be influenced by methodology, but that is too easy to say. It is a fact that one can condition him/herself by training certain ways of linking knowledge items. Examples of such links are the similar, the opposite, the associated, and the previous. As a creator, without being aware of it, we constantly train ourselves to use association tools.

A consequence of the novelty dogma is that products of the past lose interest pretty quickly. The market price of a product has evaporated at the moment it leaves the shop. Creativity is always regarded as a positive property of the human condition. However, because the physical side of creativity is not necessarily in sync with ethical responsibility, it can also work as a characteristic of humans that threatens humanity as well as its habitat. An often heard response to scientific lines of exploration that are under social debate (e.g., Petri dish meat, cloning) is 'because it is possible, because we can do it.'

\subsubsection{Creativity of the crowds}

Due to perspectivism, subjectivism, and perceptual error, entities are polyinterpretable but at least in the Western mechanistic world view with its focus on logical reasoning, this is not something to be keen on. Small children show a tendency to use artifacts in different ways than they were designed for. On many occasions, we correct children for that and our educational system also is prone to teach the 'proper uses' and leaves little room for free exploration. When people depended more on nature than today, it was quite common that creativity was used to find ways to apply objects from nature for different functions. A wooden branch could be used as a weapon as well as a building component. Industrial artifacts, by contrast, are usually mono-interpretable, each feature in the interface relates to one function and buttons or widgets with multiple functions are considered a nuisance and a compromise to, for instance, screen space. That does not take away, however, the tendency of humans to explore alternative functions. Designers employ their own creativity but unfortunately they often are insufficiently aware of the creative capabilities of users - what was designed out of good intentions might be misused and vice versa - what was meant to harm can also be used to help. It is the responsibility of designers to imagine or test all the abuses people could make of the designer's ingenuity. 
For most creative acts the implications are little because of the limited impact of those acts. However, in a globalized world creative acts are not limited to particular professional groups (e.g., Van Osch, \& Avital, 2010). The implications might be considerable, for good or for ill, even for creative acts with seemingly low impact. Twitter or Facebook do not add essential opportunities for communication. The absolute impact is less than, for example, the invention of a new vaccine. Due to its massive use, however, the impact of such social media is enormous and can, as we have seen in Northern Africa, considerably weigh in politically.

Autonomous creativity driven by an unstoppable physical force that combines seemingly disparate entities seems a desirable idea from a romantic point of view. For a rationalist, such a process should be kept within the ethical boundaries set by the organism or the organism will be destroyed by its own recklessness. Due to the physical-organic dualism of creativity, designers work per definition on the basis of partial rationality. This raises the question in how far they are accountable for the uses and misuses of their work. Designers do not always take the creativity of users into account, remaining unaware of potential benefits but also of potential dangers. The industrialized world glorifies newness without much consideration of its consequences. Human creativity takes the skill to make novel combinations but in check with the knowledge items to associate them with (not: anything goes). Without such ethical considerations, creativity may be a property that makes humans a threat to themselves.

\subsection{New ways of working}

If creativity is an inherent aspect of being part of nature and while nature keeps accumulating earlier component parts into new combinations, then creativity as a privilege of the gifted individual will soon be incorporated and surpassed by the collective creativity of the crowds in which the single luminary may serve as an important contributor but not as the sole inventor. Arts academies may have really wonderful people who can draw, sculpt, design clothes, etc. However, the tradition of stardom, which may function in a society of domain specialists, may be counterproductive in a global community where people of all walks of life may have good ideas (cf. Fablabs). In teaching, joint creativity may be more important than tending to the individual's needs alone. The teacher's opinion may be a touchstone but may not provide the definite answer. There are more ways to solve a puzzle, not just the one proposed by the textbook.

If this is to be taken seriously, the organization with the competitive edge will be one that creates a safe environment for their employees to ventilate ideas without negative consequences or sanctions attached: Pirate Utopias and Creative 
Free Zones. The top tier university of tomorrow would welcome initiatives from the grassroots without downplaying ideas, hijacking projects, showing ingroup favoritism, or coalition affiliation. This organization has a management that encourages new explorations instead of crippling initiatives with standards and procedures, providing plenty of time for conceptualization instead of deadlines. This organization is open to other disciplines so that the tailor of the theater costumes exchanges ideas with the technician, the set constructor, the wig studio, as well as administration. Designer and executor cooperating on an equal footing, where creativity determines the system, not the other way around. 


\section{CHAPTER 7}

\section{Conclusions}

Looking back on what we achieved during the Lorentz Workshop on Creativity (Lowcre, 2011) and its elaboration in the current book, we can formulate the tenets of our theory as follows:

Humans are not the only source of creativity in the universe. If we, out of parsimony, adhere to the familiar understanding that the core of creativity is to combine existing entities into a novel entity never encountered before, non-human creativity can be found in natural history as well as in physical nature. Given that humans are not separated from nature but an integral part of it, all human activity can be regarded as being part of nature, including things commonly considered 'unnatural' such as culture and technology. Human creativity, therefore, can be considered a special case of creativity that occurs 'naturally' in the world. We believe combinatory creativity to be one of the driving forces in the universe, inherited by all and existent in all; in other words, creativity is non-exclusive. It expresses itself in all walks of life, not just the traditional domains of arts and sciences.

At the physical level, the creation of novel combinations starts as pure coincidence. When two hydrogen atoms first met with an oxygen atom, they combined into the first water molecule, thus reducing the entropy of the universe. These molecules bonded with yet other molecules, reacting into combinatory structures or 'compounds' of increasing complexity without any (human) agency involved. The emergence of self-replicating DNA molecules was the tipping point in this respect. DNA helped to create enzymes, which created the chemical reactions we now call life. Since then, molecules more 'purposefully' combined together to establish and conserve an evolutionary line. Coincidence was reduced but not expelled from the system because every now and then mutations happened ('disruptions'), creating completely new lineages from the old. The function of randomness and mutation, or the imperfection of the system, is to be prepared with new features and qualities for a changing environment. This way, over millions of years, single-celled organisms or Protista mutated into Sequoia trees as well as whales and gorillas.

The special thing about human creativity is that it not only incorporates the physical, coincidental, side of doing lucky findings (called 'serendipity'), 
it can actually deliberately and purposefully search for unique combinations in the mind (called 'imagination'), optimize the idea in advance, before bringing it concretely into existence. Computer simulations of the process of novel combination making and optimization in view of some objective, therefore, can be regarded as functionally creative although the system that produces such novelty is not biological.

In physical and organic creativity, component parts combine on the basis of complementarity. That is, those distinctive features are combined that do not repulse one another but establish some local balance, resulting into a decline of dissimilarity between the combined parts compared to the earlier situation. The result is something entirely new given that statistically, the event did not occur before in a particular sample. For instance, yellow and blue are different colors but when they were mixed together for the first time, the resulting new color was green. Green is more adjacent to both yellow and blue than yellow and blue are to each other. Moreover, green dissolves the dissimilarity between the original colors as compared to the unmixed situation. Sodium metal plus chlorine gas once became table salt, closely combining two very different substances with a few percent of covalency or 'shared energy'. In human creativity, the reduction of dissimilarity between two (associatively) disparate entities is done on the insight (in imagination) that similarity is increased. Because humans in a creative mode tend to look for things that are the same across domains, the anticipation of finding similarity helps to select and adapt features such that the impact of distinctive features is lessened, reducing dissimilarity. This way, one may invent from Salsa dancing and Aikido martial art a new discipline of body motion called "Salkido."

Because humans can make combinations in imagination and because no system can avoid coincidental events, organic (i.e. human) creativity is susceptible to perceptual error. Perception has a double function. It limits the design space due to the information it can observe and hence, work with. It is harder for humans to create in the infrared than in normal light because you simply cannot see what is out there. Artificially opening up more domains through instruments and learning things through books and experience, of course, widen the design space. Perceptual error is an enabler of creativity because it switches the perspective on deeply rooted beliefs, concepts, and theories of what is available in the world and how to deal with it. Incidental flaws and errors draw in information domains not considered beforehand, increasing the opportunities for new cross-fertilizations. Playfulness has the same kind of function. Fooling around with objects and ideas just for the fun of it leads to unexpected combinations that would not have been observed if someone would stick to known practices. 
This opening up and closing in of the design space within the universe of information about us takes the shape of an (imperfect) sinusoidal curve. It may happen as a function of wider or narrower perception. The design space decreases also because making more complex structures decreases the possibilities of using component parts in other constellations (cf. scarcity of raw materials). The demand of novelty may also decrease the design space. Reproduction of the same creation may increase the availability of design elements but does not increase the possibility of making a new combination. Only by deconstruction or decay, component parts of a structure are set free to be combined into new structures once more: The design space increases. Eating is detaching molecules from chunks of matter that originate from other kinds of organisms to build up or restore an individual structure.

Within the sinusoidal boundaries of the design space, combinatory creative search shows emergent fractal behavior. Whereas the combinatory breakthrough to new domains is a physically driven disruption (cf. coincidental mutation), the smaller incremental combinations that follow from it, the organic evolution of the creation, including optimization work, show a fractal pattern. Fractal or nearly self-similar repetition of behaviors can be observed throughout nature on almost any scale - at the nano-level in the magnetization of semiconductors, at the mesolevel in neuronal firing patterns of the human brain and at the macro-level in the shapes of vast mountain ranges. Fractal search turns out to be more efficient than the randomness physics exploits in finding novel combinations. Just like the roots of a tree search for nutrients in a fractal way of growth, human creativity searches for unoccupied niches of information in the design space. 


\section{CHAPTER 8}

\section{Coda}

\section{Futurist perspectives}

The implications of an integrative approach to creativity that we just tried, could be profound, providing fruitful new avenues of inquiry into the numerous fields that consider related issues, from social sciences to neuroscience, to physics. If we do identify a unified creativity, this could provide great insights into our nature and our origins. We may be able to test this theory with simulations of the computational models of creativity. These computational models of creativity may result in more creative machines, with the prospect that our machines could invent solutions to hard problems, in ways that may augment or rival the human brilliance. In this pursuit, we acknowledge that the fragmented approach to creativity research must give way to a more integrative approach, grounded in mathematics and fundamental physics. As we pursue fundamental creativity theories, we note that many examples of creativity naturally arise through basic physical processes - from particle emergence, to star formation, to evolution, neurobiology, psychology, society, and beyond. If we can identify principles that generalize across these phenomena, then we may find some fundamental basis for human creativity, grounded in physics.

What is the shape of a creative universe? Considering that the universe is not done evolving, what comes next? Machine awakenings? The redesign of humans to be smarter and more creative? We can use these results to create new algorithms and computing technologies to engender androids with improved powers of imagination and creativity. For such a hyper-brilliant future to be feasible and desirable, however, we need to increase not just raw intelligence and creativity, but also our wisdom. To address this, we must consider the ethics of creativity, including computational models of ethics for use in machine intelligence.

Common to all creative processes in nature, we find combinatory pattern emergence. Novel patterns of matter and energy manifesting - coming into play, and disrupting. The differences among sundry examples of creativity in nature appear to relate both to differing levels of complexity, and the distinguishing functionality of certain patterns, such as in memory, survivability in an environment, and the ability to yield additional creativity. In other words: Some patterns will simply be more creative than others. If we can formalize the mathematics and physics of creativity, we may unlock the mysteries of mind, our place in the universe, and ways to evolve towards still-higher states of creativity. 


\section{References}

Albert, R. S., \& Runco, M. A. (1999). A history of research on creativity. In R. J. Sternberg (Ed.), Handbook of creativity (pp. 16-31). Cambridge, UK: Cambridge University.

Ambrose, D. (1996). Unifying theories of creativity: Metaphorical thought and the unification process. New Ideas in Psychology, 14(3), 257-267.

Arieti, S. (1976). Creativity: the magic synthesis. New York, NY: Basic Books.

Arnheim, R. (1954). Art and visual perception: A psychology of the creative eye. Berkeley, CA: University of California.

Attridge, D. (2004). The singularity of literature. London: Routledge.

Avital, M., \& Te'eni, D. (2009). From generative fit to generative capacity: Exploring an emerging dimension of information systems design and task performance. Information Systems Journal, 4(19), 345-367.

Barron, F. (1988). Putting creativity to work. In R. J. Sternberg (Ed.), The nature of creativity: contemporary psychological perspectives (pp. 76-98). New York, NY: Cambridge University.

Boden, M. (1990). The creative mind: myths and mechanisms. London: Weidenfeld \& Nicholson.

Bois, J. S. (1972). Epistemics: the science-art of innovating. San Francisco, CA: International Society for General Semantics.

Brown, T. (2008). Design thinking. Harvard Business Review, 86(6), 84-92.

Carter, B., \& Knight, D. (2008). Semiotic domains and non-textual technologies. Available at: http://sites.wiki.ubc.ca/etec510/Semiotic_Domains_and_Non-Textual_Technologies

Carter, R. (2004). Language and creativity. The art of common talk. London: Routledge.

Casti, J. L. (1994). Complexification: Explaining a paradoxical world through the science of surprise. New York, NY: Harper Collins.

Chomsky, N. (1966). Cartesian linguistics. A chapter in the history of rationalist thought. New York, NY: Harper \& Row.

Clark, A. (2003). Natural-born cyborgs: minds, technologies, and the future of human intelligence. New York, NY: Oxford University.

Csíkszentmihályi, M. (1988). Society, culture, and person: a systems view of creativity. In R. J. Sternberg (Ed.), The nature of creativity: contemporary psychological perspectives (pp. 325339). New York, NY: Cambridge University.

Csíkszentmihályi, M. (1996). Creativity: flow and the psychology of discovery and invention. New York, NY: Harper Perennial.

Dawkins, R. (1976/1989). The selfish gene. Oxford, UK: Oxford University.

De Beaugrande, R. (1978). Linguistics and Creativity. Paper presented at the Interdisciplinary Conference on Linguistics (Louisville, Kentucky, April 1978).

Dewey, J. (1916). Democracy and education: an introduction to the philosophy of education. New York, NY: Macmillan.

Elsom-Cook, M. (2001). Principles of interactive multimedia. New York, NY: McGraw-Hill. 
Fairbanks, M. S., \& Taylor, R. P. (2011). Measuring the scaling properties of temporal and spatial patterns: From the human eye to the foraging albatross. In S. Guastello \& R. Gregson (Eds.), Nonlinear dynamical analysis for the behavioral sciences using real data. New York, NY: CRC.

Freud, S. (1986). On creativity and the unconscious. The psychology of art, literature, love, and religion. New York, NY: Harper Collins.

Gardner, H. (1988). Creative lives and creative works: a synthetic scientific approach. In R. J. Sternberg (Ed.), The nature of creativity: contemporary psychological perspectives (pp. 288321). New York, NY: Cambridge University.

Gibson, J. J. (1966). The senses considered as perceptual systems. Boston, MA: Houghton Mifflin. Giedion, S. (1941). Space, time and architecture: the growth of a new tradition. Cambridge, MA: Harvard University.

Giedion, S. (1948). Mechanization takes command, a contribution to anonymous history. New York, NY: Oxford University.

Gladwell, M. (2002). The tipping point: How little things can make a big difference. Boston, MA: Little, Brown, and Company.

Goswami, A. (1996). Creativity and the quantum: a unified theory of creativity. Creativity Research Journal, 9(1), 47-61.

Greene, R. T. (2001). A model of 42 models of creativity, plus a new model derived from selecting 7 of them. Available at: http://independent.academia.edu/RichardTaborGreene/ Papers/9086/A_Model_of_42_Models_of_Creativity

Greene, R. T. (2004). A model of 60 models of creativity for studying how particular repertoires of such models in creators affect their creativity. Available at: http://www.scribd.com/ doc/2162318/A-Model-of-60-Models-of-Creativity

Gruber, H. E., \& Davis, S. N. (1988). Inching our way up Mount Olympus: The evolving-systems approach to creative thinking. In R. J. Sternberg (Ed.), The nature of creativity: contemporary psychological perspectives (pp. 243-270). New York, NY: Cambridge University.

Hahn, R. (1971). Anatomy of a scientific institution: The Paris Academy of Sciences, 1666-1803. Berkeley, CA: University of California.

Heilman, K. M., Nadeau, S. E., \& Beversdorf, D. O. (2003). Creative innovation: possible brain mechanisms. Neurocase, 9(5), 369-379.

Heine, B. (1997). Cognitive foundations of grammar. New York, NY: Oxford University.

Heisenberg, W. (1952). Die Physik der Atomkerne [The physics of atomic nuclei]. London: Taylor \& Francis.

Helmholtz, H. L. F. (1969). Treatise on physiological optics. New York, NY: Dover Publications.

Hennessey, B. A. \& Amabile, T. M. (1988). The conditions of creativity. In R. J. Sternberg (Ed.), The nature of creativity: contemporary psychological perspectives (pp. 1-38). New York, NY: Cambridge University.

Hoorn, J. F. (2012). Epistemics of the virtual. Linguistic approaches to literature 12. Amsterdam, Philadelphia, PA: John Benjamins.

Johnson-Laird, P. N. (1988). Freedom and constraint in creativity. In R. J. Sternberg (Ed.), The nature of creativity: contemporary psychological perspectives (pp. 202-219). New York, NY: Cambridge University.

Kahneman, D., \& Tversky, A. (1984). Choices, values and frames. American Psychologist, 39(4), 341-350. doi:10.1037/0003-066X.39.4.341

Kirkham, R. L. (1984). Does the Gettier problem rest on a mistake? Mind, 93(372), 501-513.

Kelly, K. (2010). What technology wants. New York, NY: Viking. 
Kuhn, T. (1962). The structure of scientific revolutions. Chicago, IL: University of Chicago.

Landy, M. S., Maloney, L. T., Johnston, E. B., \& Young, M. (1995). Measurement and modeling of depth cue combination: in defense of weak fusion. Vision Research, 35, 389-412.

Langlotz, A. (2006). Idiomatic creativity. Amsterdam, Philadelphia, PA: John Benjamins.

Latour, B. (2007). Reassembling the social: An introduction to actor-network-theory. Oxford: Oxford University.

Lowcre, M. M. M. (2011). Creativity: Meaning, Mechanisms, Models. Lorentz Workshop in collaboration with KNAW and NIAS (Sept. 12-16, 2011). Leiden, NL: Lorentz Center. Available at: http://www.lorentzcenter.nl/lc/web/2011/470/info.php3?wsid=470

Mandelbrot, B. B. (1982). The fractal geometry of nature. San Francisco, CA: Freeman.

Marr, D. (1982). Vision: A computational investigation into the human representation and processing of visual information. New York, NY: Freeman.

McKim, R. H. (1972). Experiences in visual thinking. Belmont, CA: Brooks/Cole.

Miller, A. I. (2000). Insights of genius. Cambridge, MA: MIT.

Molella, A. P. (2002). Classics revisited: science moderne, Sigfried Giedion. Technology and Culture, 43, 374-379.

Moran, S. (2010). The roles of creativity in society. In J. C. Kaufman \& R. J. Sternberg (Eds.), The Cambridge handbook of creativity (pp. 74-90). Cambridge: Cambridge University.

Mumford, L. (1934). Technics and civilization. New York, NY: Harcourt, Brace and Company.

Nickerson, R. S. (1999). Enhancing creativity. In R. J. Sternberg (Ed.), Handbook of creativity (pp. 392-430). Cambridge, UK: Cambridge University.

Paffen, C. L. E., Verstraten, F. A. J., \& Vidnyanszky, Z. (2008). Attention-based perceptual learning increases binocular rivalry suppression of irrelevant visual features. Journal of Vision, 8(4): 25, 1-11.

Park, G., Lubinski, D., \& Benbow, C. P. (2007). Contrasting intellectual patterns predict creativity in the arts and sciences: Tracking intellectually precocious youth over 25 years. Psychological Science, 18, 948-952.

Perkins, D. N. (1988). The possibility of invention. In R. J. Sternberg (Ed.), The nature of creativity: contemporary psychological perspectives (pp. 362-385). New York, NY: Cambridge University.

Piaget, J. (1952). The child's conception of number. Trans. C. Gattegno \& F. M. Hodgson. London: Routledge and Paul.

Poelman, W. (2005). Design for living. International Conference on Doing, Thinking, Feeling Home: The Mental Geography of Residential Environments (Oct. 14-15, 2005, Technical University Delft). Available at: http://otb.tudelft.nl/fileadmin/Faculteit/Onderzoeksinstituut_ OTB/Studeren/Studiedagen/Websites_internationale_congressen/Doing,_Thinking/

Papers/doc/Conference_paper_Poelman.pdf

Pope, R. (2005). Creativity: theory, history, practice. London: Routledge.

Pope, R., \& Swann, J. (2011). Introduction: creativity, language, literature. In J. Swann, R. Pope, \& R. Carter (Eds.), Creativity in language and literature: the state of the art (pp. 1-22). Basingstoke, Hants: Palgrave Macmillan.

Ryland, S. (2011). Resisting metaphors: a metonymic approach to the study of creativity and cognition in art analysis and practice. Unpublished Doctoral dissertation, University of Brighton / University for the Creative Arts.

Schank, R. C. (1988). Creativity as a mechanical process. In R. J. Sternberg (Ed.), The nature of creativity: contemporary psychological perspectives (pp. 220-238). New York, NY: Cambridge University. 
Schaub, A., Herst, D., Surya, T., \& Agrivina, I. (2011). Intercontinental collaboration on prosthetic design. In B. van Abel, R. Klaassen, L. Evers, \& P. Troxler (Eds.), Open design now. Amsterdam: BIS.

Schrödinger, E. (1944/2010). What is life? Mind and matter. New York, NY: Cambridge University.

Simonton, D. K. (1988). Creativity, leadership, and chance. In R. J. Sternberg (Ed.), The nature of creativity: contemporary psychological perspectives (pp. 386-426). New York, NY: Cambridge University.

Sennet, R. (2008). The craftsman. New Haven, CT: Yale University.

St. Clair, R. N. (2002). Metaphor and linguistic creativity. Keynote Address: Trinity University. Available at: http://epistemic-forms.com/R-creativity.html

Sternberg, R. J. (Ed.). (1988). The nature of creativity: contemporary psychological perspectives. New York NY: Cambridge University.

Sternberg, R. J. \& O’Hara, L. A. (1999). Creativity and intelligence. In R. J. Sternberg (Ed.), Handbook of creativity (pp. 251-272). Cambridge, UK: Cambridge University.

Taylor, C. W., (1988). Approaches to and definitions of creativity. In R. J. Sternberg (Ed.), The nature of creativity: contemporary psychological perspectives (pp. 118-119). New York, NY: Cambridge University.

Torrance, E. P. (1988). The nature of creativity as manifest in its testing. In R. J. Sternberg (Ed.), The nature of creativity: contemporary psychological perspectives (pp. 43-75). New York NY: Cambridge University.

Van Abel, B., Klaassen, R., Evers, L., \& Troxler, P. (Eds.). (2011). Open design now. Amsterdam: BIS.

Van Dijk, D., Kresin, F., Reitenbach, M., \& Rennen, E. (2011). Users as designers. Amsterdam: Waag Society.

Van Osch, W., \& Avital, M. (2010). Generative collectives. In Proceedings of the International Conference on Information Systems (ICIS), Saint Louis, Missouri.

Von Bertalanffy, L. (1968). General systems theory: foundations, development, applications. New York, NY: George Braziller.

Von Graevenitz, A. (2009). Joseph Beuys' letzte Leitern Scala Libera und Scala Napolitana (1985). In M. Vahler, M. Vöhler, \& D. Linck (Eds.), Grenzen der Katharsis in den modernen Künsten: Transformationen des aristotelischen Modells seit Bernays, Nietzsche und Freud (pp. 255-292) [Boundaries of catharsis in the modern arts: Transformations of the Aristotelian model since Bernays, Nietzsche and Freud]. Berlin, GE: Walter de Gruyter.

Wenger, W., \& Poe, R. (1996). The Einstein factor: a proven new method for increasing your intelligence. New York, NY: Random House.

Ward, T. B., Smith, S. M., \& Finke, R. A. (1999). Creative cognition. In R. J. Sternberg (Ed.), Handbook of creativity (pp. 189-212). Cambridge, UK: Cambridge University.

Wolpert, D. M, Ghahramani, Z., \& Jordan, M. I. (1995). An internal model for sensorimotor integration. Science, 269, 1880-1882.

Zawada, B. (2006). Linguistic creativity from a cognitive perspective. Southern African Linguistics and Applied Language Studies, 24(2), 235-254. 


\section{Appendix 1}

Double click and scroll to explore models of creativity (after Greene, 2001; 2004).

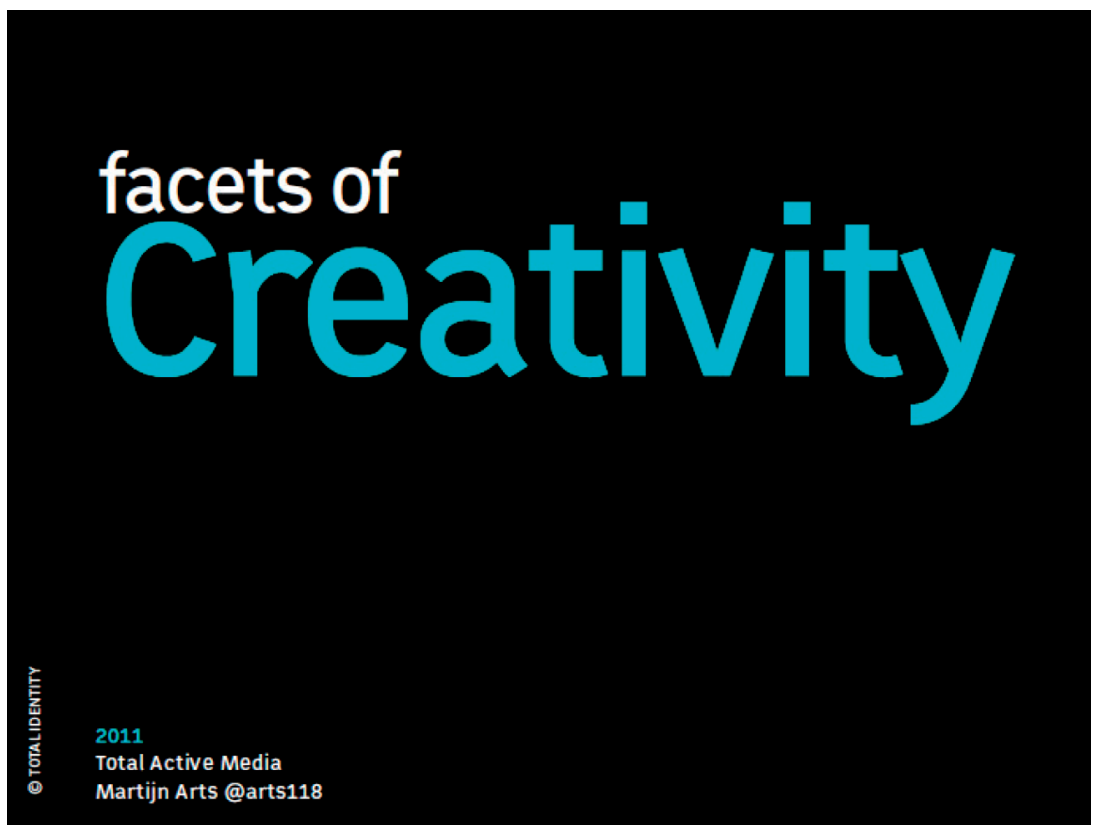




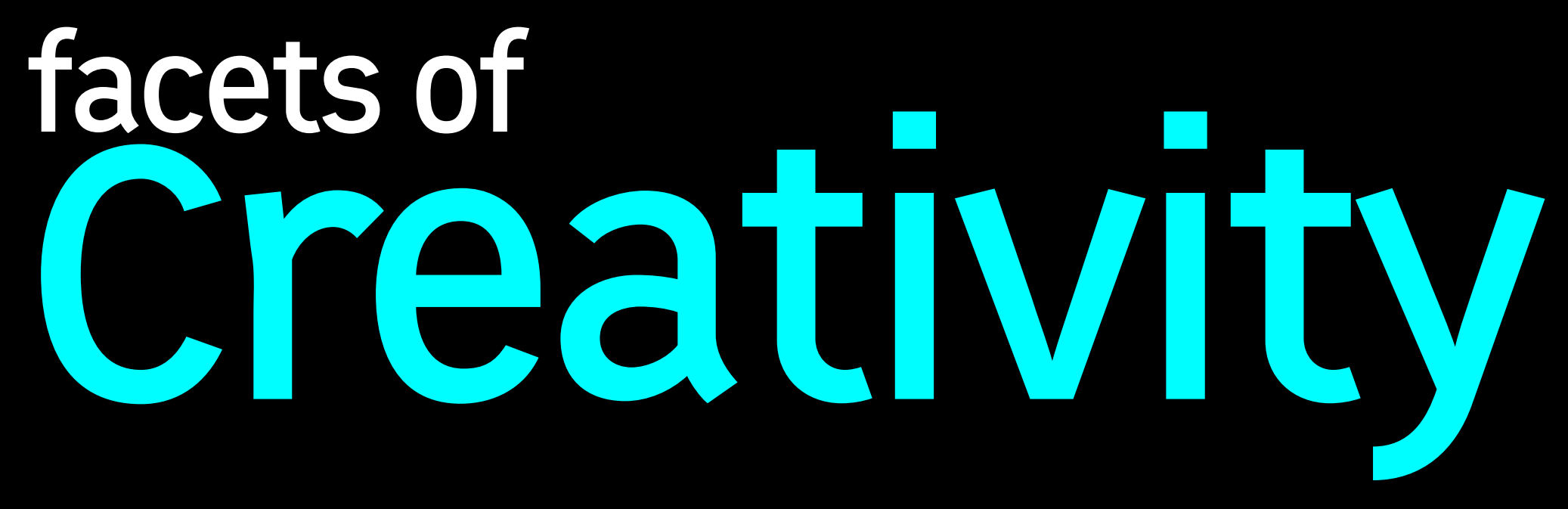

\section{1}

Total Active Media

Martijn Arts @arts118 
Facets of

Creativity

and models

Creativity has been subject for
research for a long time. Many Within minutues you can find describe the matter. All a
different in their approach.

Richard Tabor Greene of creativity in 2004. A model
of dink, there is no need
new models to describe

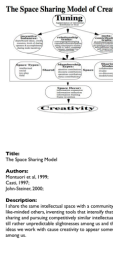

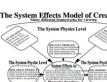

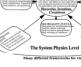

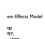

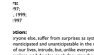

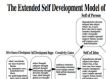

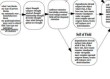

$=$

$\equiv$

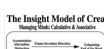
I)

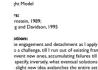

$\pm$

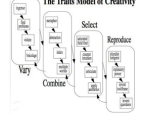

$=$

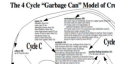

$=$

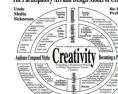

-
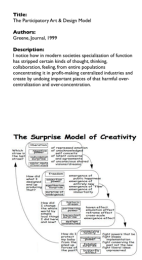

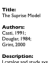

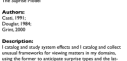

要

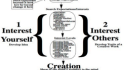

$=$

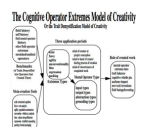

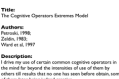

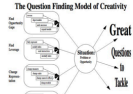

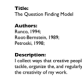

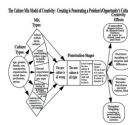

$=$
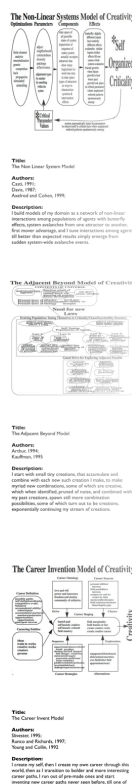

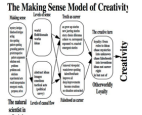

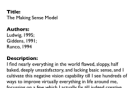

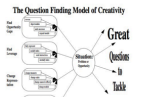

men

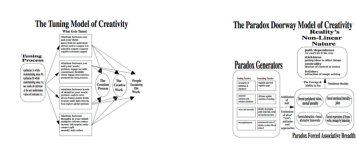

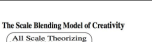

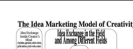

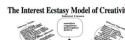

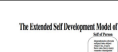


Facets of

Creativity

meaning, mechanism

and models

Creativity has been subiect for Tesearch for a long time. Many
models have been developed. Within minutes you can find wscribe the matter. All are

Richard Tabor Greene of creativity in 2004 . A model of models. Quite overwhel ming!

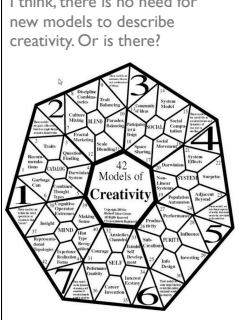

Det eve the model of Green is

valuable as glossary of 42

do ight to all facets of

I use metaphors to depict all

models in a three-dimension

way. Cryystal is the first
metaphor that has a perfect

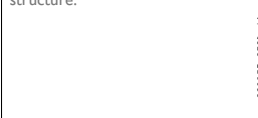

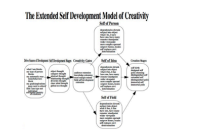

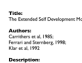

$=$

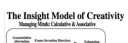

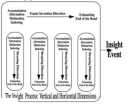

$\pm$

P.

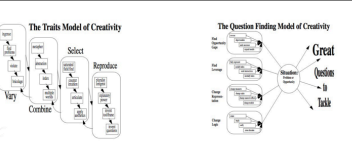

눌

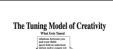

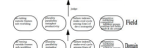

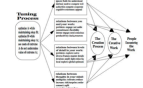

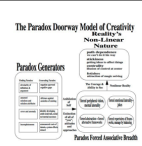

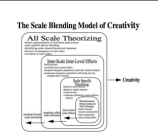

政:

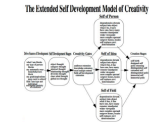

E $\quad E$

$\underline{E}$

$=$

$E$

(a)

-

manom

$=$

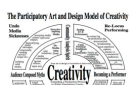

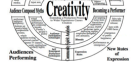

$=$

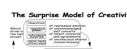

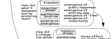

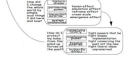

$=$

$\pm$

F

$\left\{\begin{array}{l}1+1 \\ i=0\end{array}\right.$

$=$

$=$

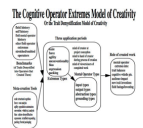

$=$

(n)

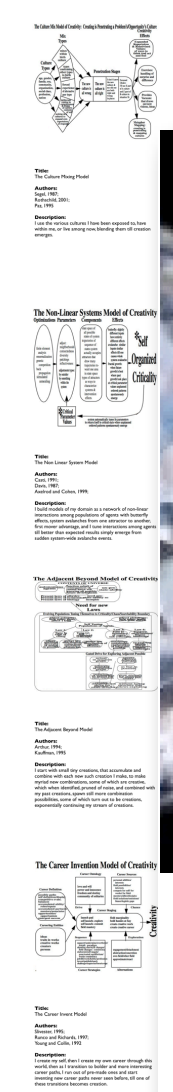

$==$
$=-=$

譬-

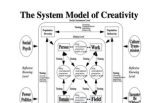

竞=

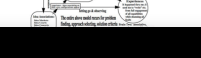

-
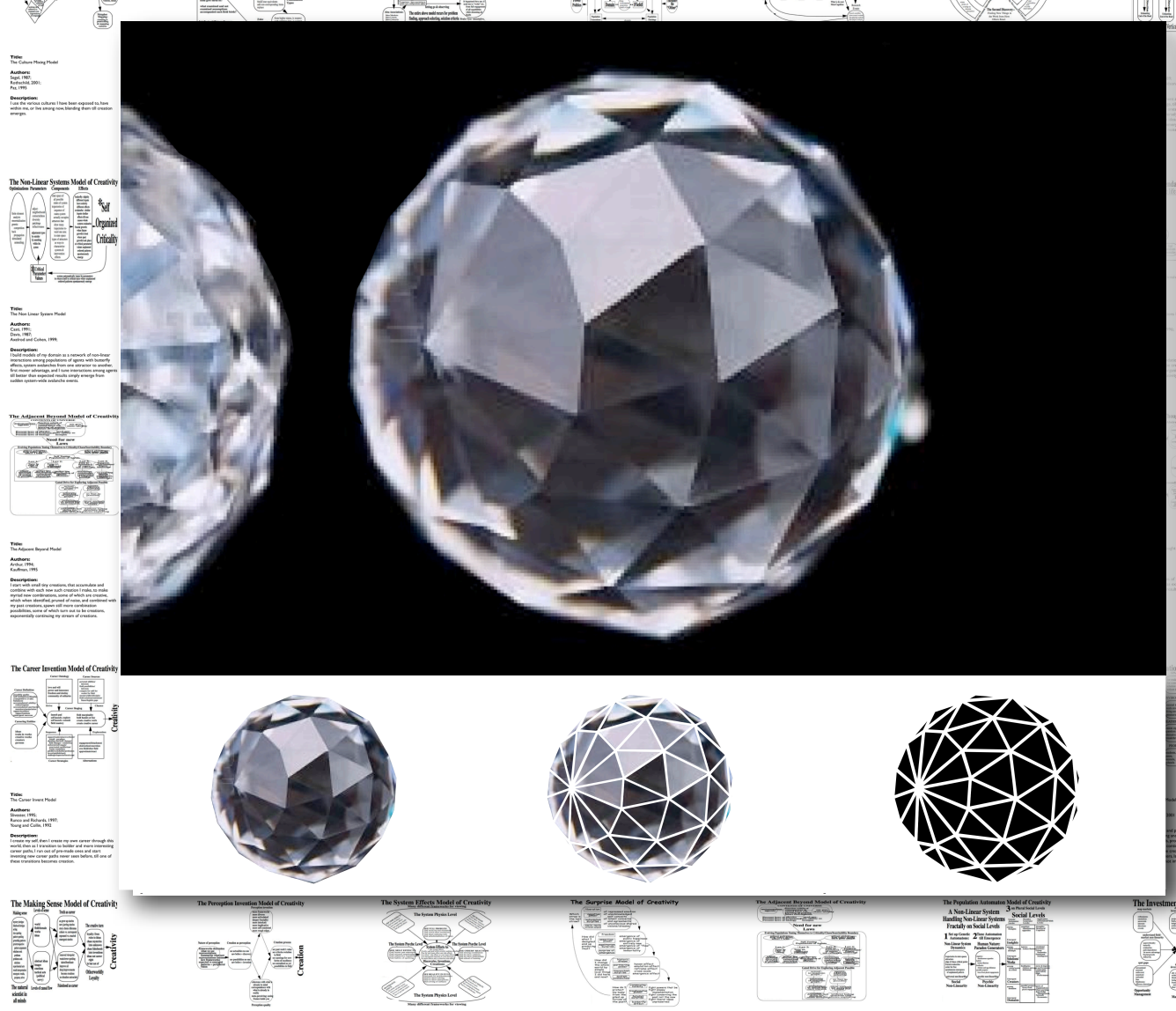

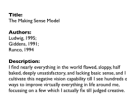

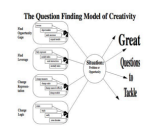

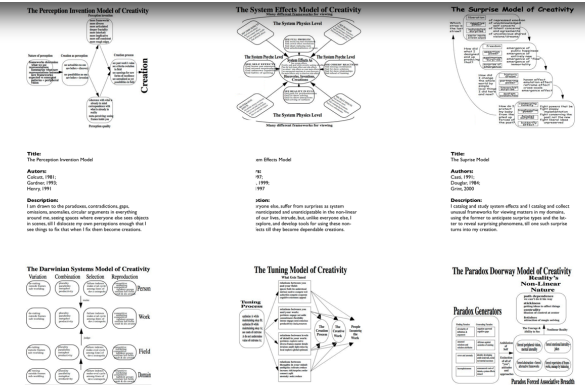

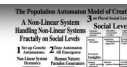

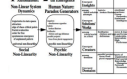

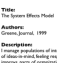

$\equiv$

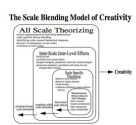

势

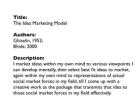

$=$

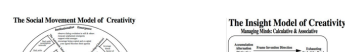

$(-1)$ $\sqrt{1-10}$

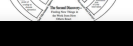

$=\{t$

衰

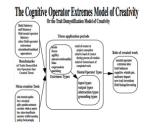

$\underline{3}$

The

$\stackrel{=-\infty}{=-\infty}$

$=$

$\frac{1}{2}$

$=$

$\equiv$

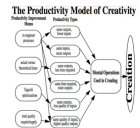

$=$

$=$

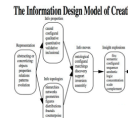

$\pm$
$=$

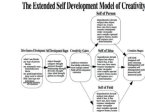

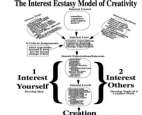

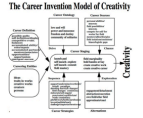

$=$ 或:

$\pm$

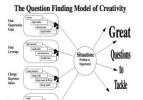

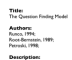

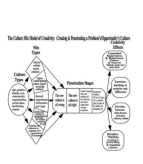

$=$

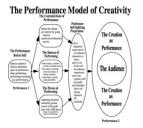

$=$

$\pm$

1
$n^{2}$

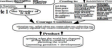

$=$

플

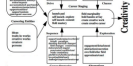


Facets of

meaning, mech

and models

Creativity has been subject for
researc for a long tieme.Mary
models have been developed. Wertif miny sciestificic models th different in their approach,

Richard Tabor Greene

of creativity in 2000 . A . model
of models. Quite overwhelming

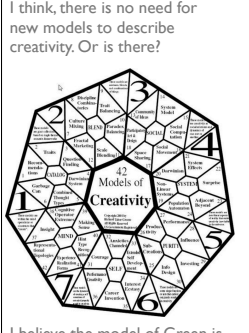

(1)

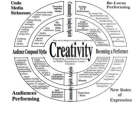

$=$

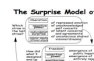

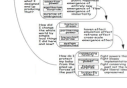

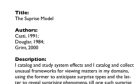

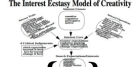

$=\{\}$

衰

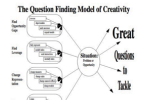

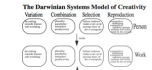

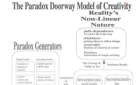

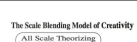

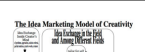

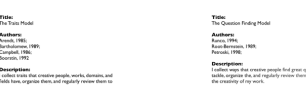

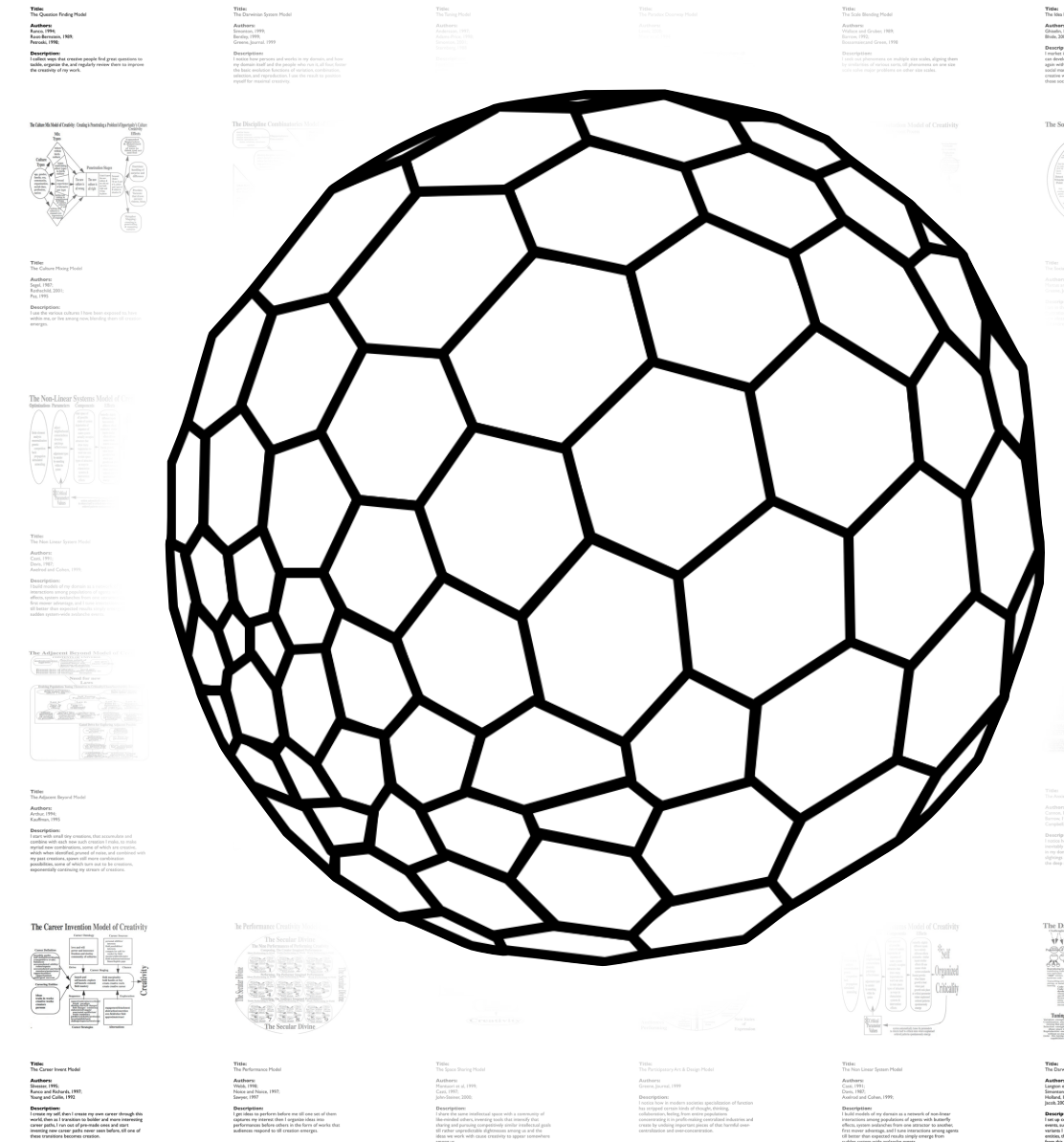

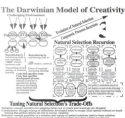

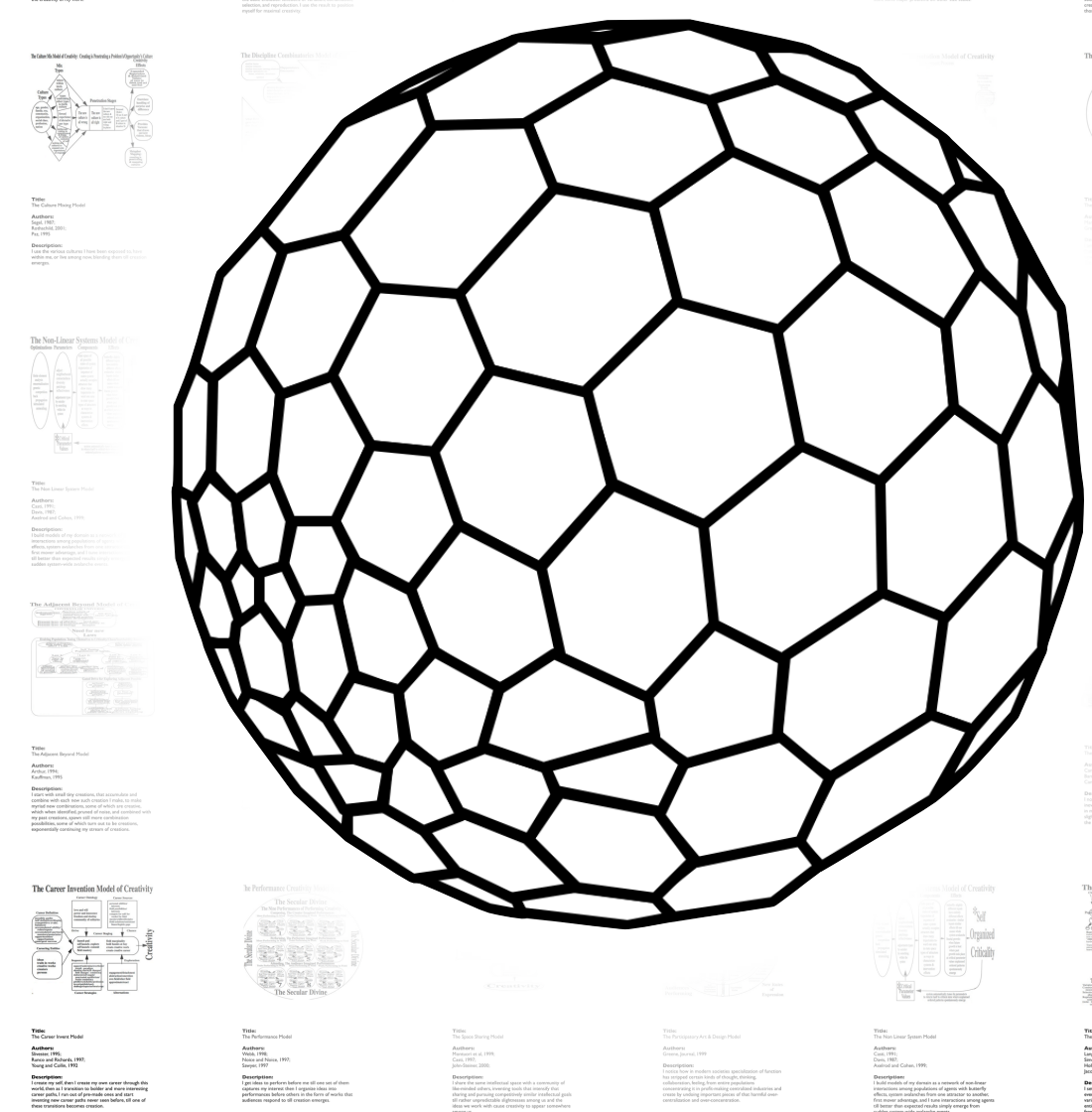

寒

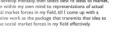

$\pm$
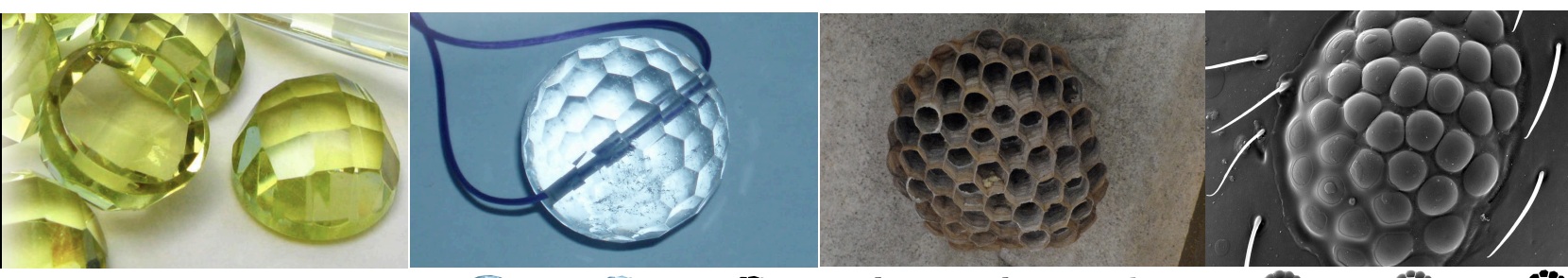

(2)

6

\%

$=$

$=$

Dit.

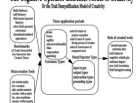

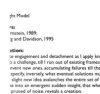

$\stackrel{\mathrm{mat}}{=}$

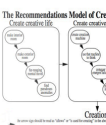

$=$
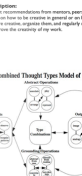

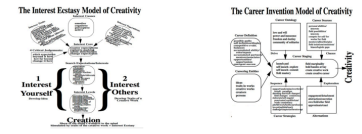

产

-

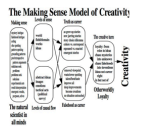

蓑

$\equiv=$

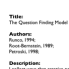

$=$

$-\frac{1}{1}$

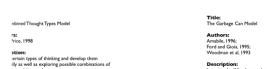

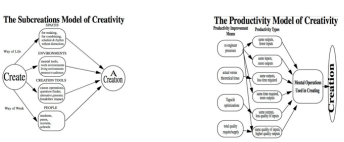

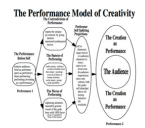

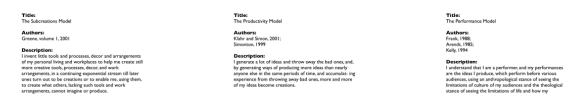

61

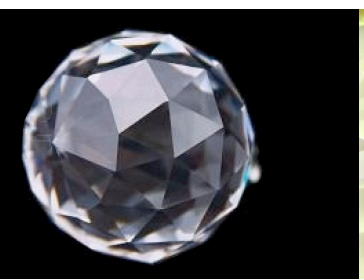

06

-

$\%$ 
Facets of

\section{Creativity}

meaning, mechanism and models
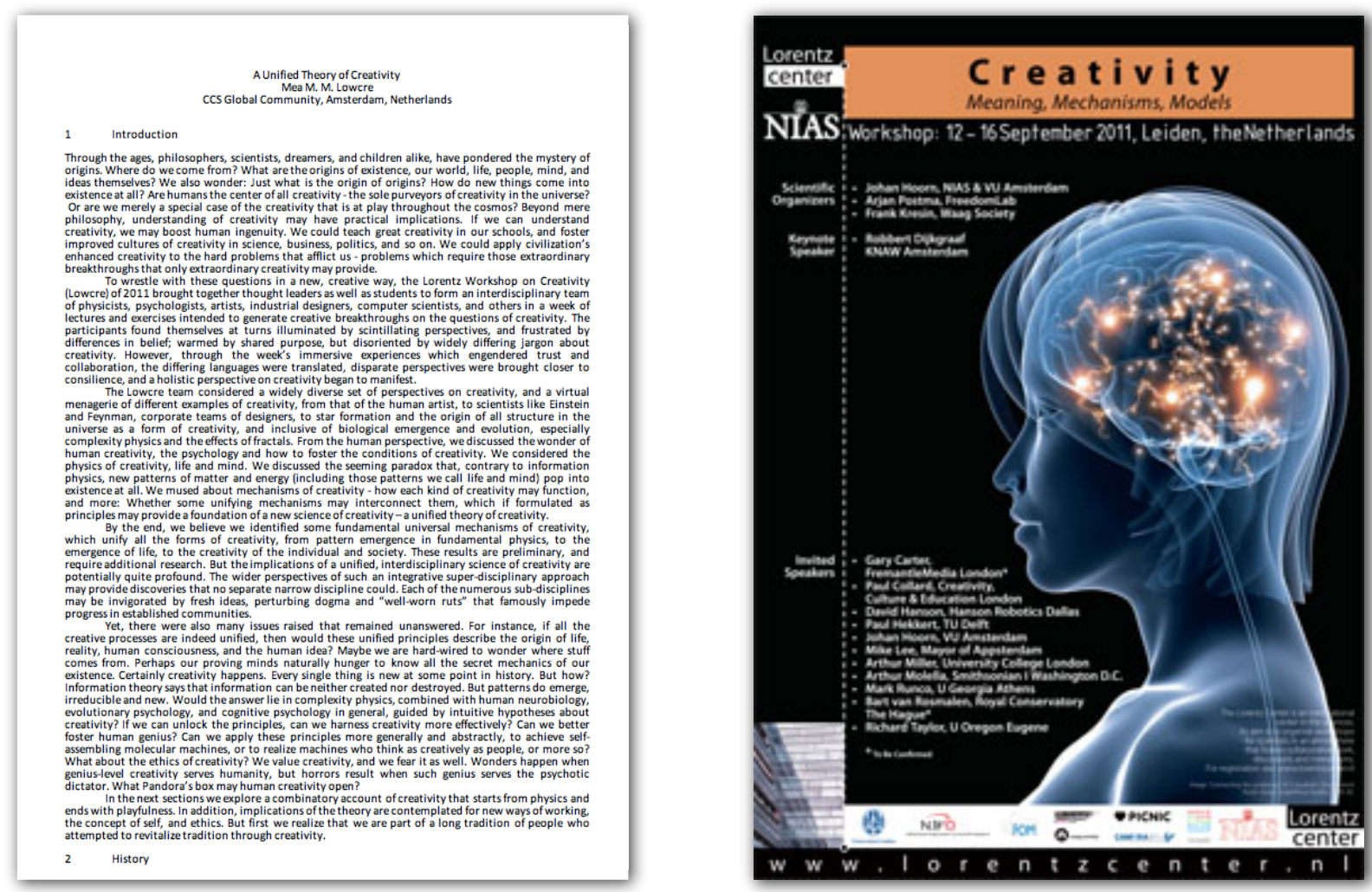


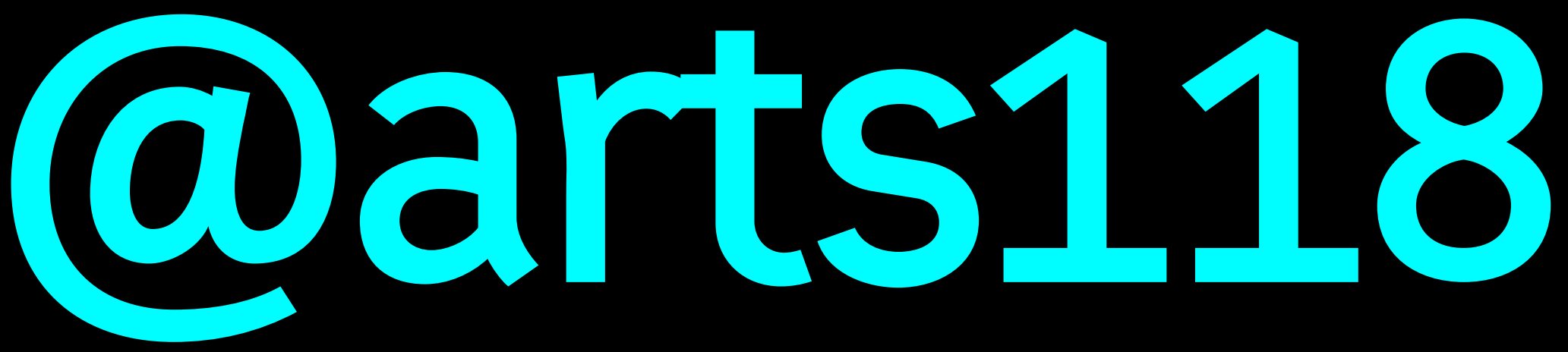

2011

Total Active Media

Martijn Arts @arts118 
A group of international top scientists from a diversity of disciplines sat together for five days with artists, designers, and entrepreneurs to develop a trans-disciplinary theory of creativity. Organic Creativity and the Physics Within assumes that creativity is a quality of nature visible in physics as well as in psychology, its basis being combinatorics, coincidence, complementarity, and fractal emergence. The authors prompt a mechanism cutting through particle physics, perception, psychology, and culminating into playfulness. Organic Creativity and the Physics Within connects us to the universality of nature's creativeness.

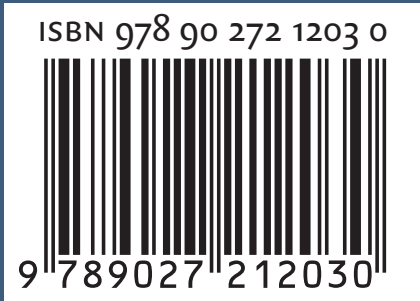

\section{John Benjamins Publishing Company}

